\title{
"Otros" mundos en la vitrina. Los catálogos de las exposiciones universales y la reproducción del discurso colonialista occidental del siglo XIX
}

\author{
"Other" worlds in the showcase. \\ The catalogs of universal exhibitions and the reproduction of the \\ Western Colonialist discourse during the XIX century \\ DOI: https://doi.org/10.5377/koot.v0i11.10743 \\ URI: http://hdl.handle.net/11298/1199
}

Guillermo Cubero Barrantes

Museólogo

Museo de Cultura Popular (MCP), UNA, Costa Rica.

guillermo.cubero.barrantes@una.cr

\section{Resumen}

Fecha de aceptación: noviembre 2019

En el presente artículo se estudia la reproducción del discurso colonialista occidental en las exposiciones universales de finales del siglo XIX. Para esto, el autor recurre al estudio crítico del discurso de los Catálogos preparados para dichas exposiciones por los países participantes. En los cuales encuentra una serie de tendencias sintomáticas en el discurso occidental, tanto conceptuales como semánticas, que evidencian contextualmente el carácter etnocentrista del discurso dominante en occidente, así como la apropiación de un discurso eurocentrado por parte de Estados Unidos como potencia emergente.

Palabras clave: América - Descubrimiento y exploraciones - Catálogos. América - Historia - Colonización - Catálogos. Exposiciones en museos. Museografía.

\begin{abstract}
This article aims to study the reproduction of Western colonialist discourse in the universal exhibitions in the late nineteenth century. In order to achieve this, the author resorts to the critical study of the discourse used in the Catalogues that the participating countries prepared for said exhibitions. A series of symptomatic tendencies in Western discourse can be found there-- both conceptual and
\end{abstract}


semantic--; they are contextually evidenced in the ethnocentric nature of the dominating discourse in the West, as well as the appropriation of a Eurocentric discourse by the United States as an emerging power.

Key words: America - Discovery and explorations - Catalogs. America History - Colonization - Catalogs. Museum exhibitions. Museography.

\section{Introducción}

Las grandes exposiciones internacionales de finales del siglo XIX y principios del siglo XX, no fueron otra cosa que el contacto comercial entre potencias emergentes y proto-naciones que apenas se encontraban en lo que se podría considerar su infancia. Más allá de la particularidad de los grandes eventos, estos formaron parte de un proceso inicial de grandes transacciones económicas, que dieron lugar a las profundas inequidades que han tenido lugar más de un siglo después. Para ese momento había grandes diferencias culturales, pero los países denominados "de ultramar" poseían inimaginables riquezas naturales que debían ser conocidas e inventariadas. La estrategia de las grandes exhibiciones fue la de intercambiar literalmente "oro por cuentas de vidrio", y se centró en deslumbrar a los países no europeos con la idea de que el modo de vida capitalista europeo era un ideal al que debía aspirarse. Ellos compartirían con el resto del mundo ese magnífico "nivel de vida" y el resto del mundo pagaría a cambio con sus riquezas naturales.

Es casi inevitable mencionar la expansión colonialista europea que tuvo lugar en el contexto de las exposiciones universales del siglo XIX, sin mencionar la conquista de América, ya que, si se tiene en cuenta el proceso expansionista de la episteme occidental, como un todo, podría éste ser dividida en tres grandes momentos, a su vez, considerados como una reproducción y exacerbación cada uno de su precedente: el descubrimiento y conquista de América en el siglo XVI, las grandes exposiciones universales en el siglo XIX y el momento actual, con la estandarización -y empobrecimiento- de una cultura global promovida por la revolución tecnológica.

Teniendo en cuenta lo anterior, es preciso llamar la atención sobre el poder de exterminio, de estos procesos de expansión occidental, y su efecto sobre las epistemologías y los saberes localizados a lo largo de todo el planeta. Si la conquista de América significó la más ambiciosa empresa de dominación y subordinación colonial que haya conocido la humanidad (Maldonado Torres, 2007), es preciso tener en cuenta que ésta se verificó de una manera tan gradual que todavía seguimos sintiendo sus efectos. El impacto producido por las 
exposiciones universales en el siglo XIX, por el contrario, fue tan sincrónico, global y drástico, que sus efectos han sido devastadores para los recursos naturales del planeta, explotados hasta su agotamiento total, para los modos de vida y saberes locales que han sido arrasados por el establecimiento de normas, la lógica de mercado y la obsesión con el paradigma cartesiano.

Esta reproducción discursiva que tiene lugar en el contexto de las grandes exposiciones universales deja clara la diferencia entre colonialidad y colonialismo: mientras el colonialismo es el proceso que surge del descubrimiento de América, la colonialidad es la forma de dominación "ideológica" que ha sobrevivido hasta la actualidad. Es una forma de dominación que se ampara, ya no tanto en el poder de la espada -ego conquiro- sino en el poder sugestivo de la ideología de "raza" que, apoyada en los paradigmas de la ciencia cartesiana -ego cogito-, utiliza una lógica maniquea basada en razonamientos biológicos para colocar a la humanidad en dos posiciones: una de superioridad y otra de inferioridad (Maldonado Torres, 2007). Dicho de otra manera, el proceso de expansión de Occidente no es otra cosa que la profundización, reactualización y reproducción de la lógica del colonialismo y el racismo como sus ideas básicas de dominación, proceso de expansión que ha sido identificado en Occidente con la idea de modernidad.

Para el análisis de lo anterior, se ha recurrido especialmente al estudio de las tensiones que se derivan del estudio crítico del discurso (ECD) de los catálogos preparados para dichas exposiciones. En cuanto al corpus documental base para este estudio, se trata de los catálogos de las exposiciones universales en las que participaron los países centroamericanos a finales del siglo XIX, es decir, los textos museológicos generados tanto en Centroamérica como en Europa, que hacen referencia de una u otra forma, a descripciones y autodescripciones sobre el istmo, sobre Europa y Estados Unidos, estudiados desde su paratextualidad -introducciones, prólogos, prefacios, entre otros- - La selección del corpus obedece a una serie de criterios que permiten tanto la comparatividad como establecer correlatividad en términos históricos y sociales. Entre los aspectos a tener en cuenta, son importantes aquellos que están articulados desde las potencias europeas y Estados Unidos en el siglo XIX y que muestran relación con catálogos articulados desde Centroamérica en la misma época.

Los documentos considerados son básicamente de "autodescripción" del "yo europeo" y muy poco sobre "el otro centroamericano", de tal manera que se recurre a la transtextualidad, es decir, que se incluyen algunos documentos escritos en el contexto espacio-temporal-cultural de las grandes exposiciones universales, para buscar en ellos una ampliación sobre las descripciones del "otro centroamericano" que ayuden a completar la imagen. 
Uno de los ejes terminales centrales se encuentra en las tendencias encontradas en dichos documentos. La noción de tendencia la encuentra Jorge Chen como una relación entre los contenidos del texto analizado y la realidad sociohistórica que los circunda (Chen Sham, 1999), lo cual aporta un nivel de profundización mayor en la lectura de textos, sobre todo aquellos que presentan relación problemática o contradictoria con esa realidad sociohistórica, como es el caso de los catálogos de las exhibiciones universales.

\section{La exposición del IV centenario del descubrimiento de América en Madrid de 1892}

A pesar de su carácter universal la exposición de Madrid no generó tanta discursividad escrita como sus homólogas de París. Es importante para este estudio, sin embargo, porque uno de los catálogos analizados en Costa Rica para el siglo XIX fue preparado especialmente para esta exposición.

Los documentos preparados para esta exposición fueron:

Catálogo General de la Exposición Histórico Americana de Madrid. 1892. Tomos I, II y III.

Discurso pronunciado en Madrid en el Palacio de la exposición universal de bellas artes por acontecimiento del Cuarto Centenario de Colón. Por el distinguido pintor Brasileño don Eugenio Texeira. Imprenta Universal. Madrid.15 de diciembre de 1892.

El segundo documento tiene pertinencia en este estudio debido a su carácter paratextual, es decir, forma parte de las actividades de la exposición del Cuarto Centenario, además, contiene la discursividad retórica, para ser analizada como macroestructura semántica y pragmática. No está demás, aclarar que encontrar un balance en las informaciones suministradas por los textos no es fácil, debido a su carácter retórico ipidíctico, es decir, de alabanza, pues los discursos generalmente esconden su verdadera naturaleza e intención, y se requiere de un ejercicio arduo de análisis para desentrañar las intenciones verdaderas del texto.

Por esta razón, resulta interesante dar inicio a esta discursividad relacionada con la arqueología americana exhibida en Europa, con un comentario aparecido en la Revista 168 de 1893, en el artículo titulado La Ilustración Española y Americana sobre las piezas arqueológicas de la exposición preparada por Peralta y Alfaro para la Exposición del IV Centenario en Madrid, al afirmar que ...su conjunto escapa a toda clasificación, pues solo da cuenta de lo que el indio inculto puede hacer por sí, aislado, sin influencia extraña... (S.A.). 
Con esta frase descalificadora, el comentarista deja resuelto en un ciento por ciento, la diferencia entre el mundo civilizado europeo y el no civilizado o no europeo. Este comentario despectivo y propio del racismo etnocentrista que prevalecía en el ambiente cientifico europeo del XIX, merece ser contrastado con las palabras atribuidas al artista alemán Alberto Durero, al referirse a una exposición sobre objetos precolombinos enviados por Hernán Cortés a Carlos V de España, cuatro siglos antes: ... armas maravillosas, vestidos extraños, cubiertas de cama y toda clase de cosas maravillosas hechas para el uso de la gente. Y eran tan hermosas que sería maravilla ver algo mejor (...) Y nada he visto a todo lo largo de mi vida que haya alegrado tanto mi corazón como estas cosas. En ellas he encontrado objetos maravillosamente artísticos y me he admirado de los sutiles ingenios de los hombres de estas tierras extrañas.

Lo que causa realmente "admiración" es el hecho que ante la presencia de objetos de idéntica naturaleza puedan suscitarse comentarios tan contrapuestos ¿Cuáles intenciones están detrás del texto y cuál era la realidad sociohistórica que los justificaba? Tal vez, de una manera un poco simplista se podría resumir de la siguiente manera: detrás de las palabras de Durero, estaba la visión de un humanista acostumbrado al contacto con la producción artística, que no vio en los objetos más que lo que aquellos inspiraron a su curiosidad intelectual.

Para el comentarista español del XIX, muy por el contrario, aparte de la carga etnocentrista ya señalada, se agrega la frustración y "el dolor" de la pérdida de todas y cada una de las posesiones de ultramar que otrora poseyera el Imperio Español y que ahora, estaban cayendo en manos de un nuevo modelo de dominación, el imperialismo informal, liderado por una nueva potencia emergente: los Estados Unidos. Tal era el contexto, un poco amargo, en medio del cual España intentaba resucitar de entre sus cenizas el ideario de sus glorias pasadas a través de las celebraciones del IV Centenario del Descubrimiento de América. Y, con este contrapunteo introductorio damos inicio al análisis de las obras asociadas a la Exposición universal de Madrid.

\section{Catálogo General de la Exposición Histórico Americana de Madrid}

El catálogo de Exposición del IV centenario había sido impreso en 3 tomos. Sin embargo, sobreviven los tomos I (el más voluminoso) y el III (de menor tamaño), encontrados en la Ibero-Amerikanisches Institut Biblioteck de Berlín. El primero contiene el inventario de los objetos de los Estados Unidos, lo cual explica su gran extensión, pues la mitad del mismo lo ocupa este país. Llama la atención, el carácter heteróclito de los objetos exhibidos, que van desde un peine, pinturas al óleo y objetos etnológicos. La participación de España, como era de esperarse, ocupa prácticamente todo el tomo III pues es muy extensa en comparación con los otros participantes, solamente comparable a la 
participación de los Estados Unidos en el tomo I. Este dato, aunado a las dos exposiciones universales para conmemorar el IV centenario del descubrimiento de América: en 1892 en Madrid y en 1893 en Chicago, ilustran, por sí solos, la tensión entre las dos potencias imperiales, una en franco declive, España, y otra en ascenso, Estados Unidos, una a expensas de la otra, con formas de imperialismo distintas, decadencia del imperialismo formal de España y su glorioso pasado colonial en América, y el auge del imperialismo informal de los Estados Unidos y sus ambiciones de hegemonía mundial.

Por otro lado, los catálogos de los países restantes debieron recortarse muchísimo para dar espacio a España y Estados Unidos. El de Costa Rica, por ejemplo, cuyo texto original contenía alrededor de 50 páginas, solo presenta un resumen muy reducido. Este tipo de discursividad, no necesariamente verbal, también cuenta en la retórica del dominio simbólico, dado que el nivel de la participación de la delegación de Estados Unidos deja patente su poderío y su dominio sobre los restantes países participantes.

El catálogo da inicio con una introducción-discurso, que revela las tensiones producidas por la acalorada discusión intelectual, y por las presiones del contexto sociohistórico tanto europeo como mundial. Un pequeño discurso, atribuido a Juan de Dios Rada y Delgado, presumiblemente el comisario de exposición, tiene lugar al inicio del catálogo, y se centra, como es de esperarse, en la figura de Cristóbal Colón.

Es interesante que al referirse a los países participantes, el expositor hace noticia a aquella parte del mundo que descubrió Colón y los españoles, junto a algunas naciones del norte de Europa (Catálogo Exposición Histórico Americana de Madrid, 1892). En esta parte del texto, como en muchas otras, se pueden notar ciertas tensiones derivadas de las discusiones intelectuales en torno al tema del descubrimiento, en este caso el autor parece otorgar crédito a los españoles junto al ya reconocido Cristóbal Colón, no español.

La preocupación por el carácter científico se vislumbra como una de las primeras tensiones en el texto, pues para la presentación de los distintos trabajos de exposición hay que formar grupos, como para la clasificación de los seres naturales, pues sin esto la más espantosa y estéril confusión sucedería al grato y fecundo encadenamiento de los hechos, racional y científicamente ordenados. Y prosigue aduciendo, que el orden de los objetos debe seguir un orden temporal que muestre la historia de América de manera gradual y para la presentación de dichos objetos, los diversos expositores debieron haberse remitido al aparato, es decir, que debieron sujetarse a un esquema rígido preestablecido que permitiera conocer la historia de aquellos pueblos desde esos obscuros 
periodos, (...) que llaman prehistóricos hasta los monumentos y objetos de civilizaciones adelantadas en los tiempos conocidamente históricos (Catálogo Exposición Histórico Americana de Madrid, 1892). La clasificación general dividió a los objetos en tres grandes series: Todos los monumentos y objetos de la protohistoria americana, otra... que comprenda los tiempos conocidamente históricos hasta el trascendental descubrimiento de América por Colón y los españoles, y finalmente, la del descubrimiento y de la conquista, y por lo tanto, de las influencias españolas y europeas hasta mediados del siglo XVII, época fijada por el Real decreto a que hemos de ajustar nuestros trabajos.

Esta compleja clasificación revela detrás de sí, fuertes tensiones en torno al tema de la Colonia y la Independencia, pues no solo llama la atención la reiteración de lo descubierto por Colón y los españoles, sino el hecho de que se evita a toda costa enunciación de lo colonial, lo cual es rebuscadamente sustituido por la época de las influencias. Finalmente, y de manera sintomática, el real decreto exige omitir toda información sobre el periodo posterior a la Independencia.

Luego el autor recomienda el uso de precolombino y postcolombino, categorías que justificó mediante su comparación con la España romana, visigoda o árabe que tomaron su nombre de la dominación a la que se ha visto sometida en diversos momentos de su historia. Y termina justificando al omnipresente tema de Colón, con la idea de que la historia está enlazada y en inmensa cadena une a los hombres, los pueblos y los tiempos. Habiendo perdido sus posesiones de ultramar, lo único que le quedaba a España era las nomenclaturas y los nombres, espacio simbólico por el que estaba dispuesta a luchar desde esta última trinchera que representó la Exposición del IV centenario.

El discurso continúa haciendo evidentes sus tensiones internas, reflexionando sobre la naturaleza de los pueblos americanos que tenían su civilización propia y de los elementos extraños al mismo y llevados allí por los conquistadores, además que destaca el hecho de que nadie puede poner en duda que el descubrimiento de América sea uno de los hechos más grandes de la historia de la humanidad y para la humanidad y no destacarlo en el contexto de esta exposición española es una especie de ojeriza.

Por otro lado, al referirse a todos estos hechos relacionados a la conquista y ocupación por los europeos "hay que ser justos y razonar con serena calma" pues "Colón fue y será siempre el descubridor de América", además "cualesquiera otros viajeros que pudieran haber llegado a aquellas regiones antes que Colón, no lo hicieron como este con el propósito de descubrirlas... y sus visitas quedaron obscurecidas, olvidadas y sin consecuencias para la historia y para la humanidad", y finalmente "si Colón fue el descubridor, si auxiliado por los 
españoles levantó de las aguas islas y continentes,(...) natural es que esos dos grandes periodos lleven su nombre.” (Catálogo Exposición Histórico Americana de Madrid, 1892, p. VIII).

Además de las fuertes tensiones evidenciadas, precedidas seguramente de las más agrias discusiones en torno al tema político, provocadas por el imperialismo de facto de las distintas potencias metropolitanas, incluido los Estados Unidos, que se abalanzaban de manera voraz sobre las antiguas posesiones españolas, se unieron las tensiones en torno al tema científico: si Europa evolucionó a partir de una Edad de piedra, hierro, bronce, etc. ¿Cómo abordar "esta primera rudimentaria infancia" americana?, ¿cómo enlazarla con "el periodo de los adelantos, del progreso humano, de la civilización, con sus artes y sus industrias"? .

\section{Países convocados}

La lista de los países participantes dio inicio con España, seguida de manera arbitraria por los demás participantes que, sin embargo, no se ubicaron en una categoría aparte como la de "países extranjeros" típica de las exposiciones parisinas. Los países mencionados en el Tomo I son: Dinamarca, Bolivia, Perú, Costa Rica, España, Uruguay, República Argentina, República Dominicana, Guatemala, Ecuador, Nicaragua y Estados Unidos.

\section{Estados Unidos}

Como ya ha sido señalado, la participación de Estados Unidos fue sumamente amplia si la comparamos con la de otros países. También la nomenclatura utilizada para organizar su exposición no fue menos interesante. Por ejemplo: "objetos de la América Rusa (Alaska), recuerdos de la dominación española en América, colección etnológica del Museo de los Estados Unidos, del Instituto Smithsoniano, catálogo del salón Hemenway [sic]". (Catálogo Exposición Histórico Americana de Madrid, 1892).

Aparte de los comentarios que pudo suscitar la amplia participación de Estados Unidos, también acompañó a esta presentación un interesante ensayo científico sobre las razas. Es notable la importancia de este tema en todas las exposiciones universales, tema sino central, al menos de gran trascendencia en ese momento, pues después de todo se debe tener en cuenta que sobre la idea de la raza, o mejor dicho, de la supremacía de la raza blanca sobre otras, se consolidó la colonización ideológica del imperialismo-capitalista posterior al siglo XIX.

El discurso sobre "la raza americana", da inicio con la explicación de su edad de piedra, que había desaparecido sumergida "bajo el cascajo...de lavado glacial"; 
por otro lado, "parece forzoso admitir la siguiente variedad de razas de indios norteamericanos" que son clasificados en: "autochtonous, los esquimales con cabezas largas, la raza dolichocephalica de las regiones del norte y de la costa, la raza brachicephalica del sudeste y en América del Sur, la raza dolichocephalica andeana".Este ensayo sobre "las razas" se hizo acompañar por la colección: "Crania Étnica Americana", una descripción de cráneos de diferentes tribus de América, obra reciente del profesor Rudolf Virchow.

La presentación de los Estados Unidos admite los siguientes comentarios: la presentación de objetos de la "América rusa" era un preámbulo de las intenciones "americanas" de poseer ese territorio extremadamente rico en minerales. Los "recuerdos de la dominación española" dejan entrever la diferente perspectiva "americana" de esta época, una clasificación descalificadora que justificaba la disputa de muchos de sus territorios al norte de México. Los objetos del Instituto Smithsoniano y la participación de la Universidad de Pensilvania dan cuenta del respaldo que "las instituciones científicas" mediante su discurso legitimador, otorgan al proceso de auge de la hegemonía mundial de Estados Unidos.

Por otra parte, el catálogo de sección Hemenway, muestra otra característica de la sociedad "americana": su apoyo total al coleccionismo privado, el cual se encuentra en consonancia con la protección que otorga el Estado a la propiedad privada en detrimento de las legislaciones y protecciones relacionadas con el patrimonio cultural de otros pueblos y culturas lejanas. Finalmente, su discurso sobre la "raza americana" da énfasis a una nomenclatura que intencionalmente identifica lo estadounidense con "lo americano", imagen que quedará grabada en adelante en el imaginario mundial, hasta nuestros días.

Las consecuencias del discurso de que "lo americano" era estadounidense en cuanto al derecho natural de su posesión, tuvo eco en su futura dominación del continente, y finalmente, el discurso científico racista, que identificaba diversos grupos humanos, no blancos, con categorías biológicas distintas al humano occidental, tenían un objetivo pragmático bien conocido: justificar su dominación y exterminio (Catálogo Exposición Histórico Americana de Madrid, 1892). El uso de mediciones craneales para diferenciar las razas, fue uno de los atractivos principales de la Exposición Universal de París de 1889 y la exhibición en museos, circos y cabarets de personas "de otras razas" fue moda en Europa y los Estados Unidos hasta la primera mitad del siglo XX.

\section{España en la Exposición Histórico Americana}

España aparece en varios apartados distintos, lo cual termina confundiendo un poco el "orden" y las "clasificaciones". Primero se distingue lo presentado por "la nación española", luego se presenta Cuba como parte de los territorios 
españoles, y en otro apartado aparece todo lo relacionado con la categoría de lo "precolombino" de México, de Perú, Bolivia, etc. Finalmente, España se presentó también con lo relacionado a lo "postcolombino": una cantidad considerable de documentos en papel, códices y otras riquezas de tipo documental formaban esta última colección presentada por el país anfitrión. Esta preponderancia en la exposición solo fue superada por los Estados Unidos, que como ya se ha señalado, ocupó prácticamente la mitad del amplio primer volumen del catálogo general.

España además presentó una sección denominada "geológico minera", en la que se presentaron objetos de los nuevos Estados en los cuales se había dividido el "vasto territorio que perteneció a España" en especial México, Bolivia, Perú y Chile. La colección mineralógica, geológica y paleontológica de Cuba y los objetos de Filipinas, se presentaron aparte para dar énfasis a la posesión de España sobre estas tierras. Esta sección no sólo se compuso de "objetos minerales" sino también de mapas y "los tanteos geológicos" realizados en Cuba, Puerto Rico y Santo Domingo.

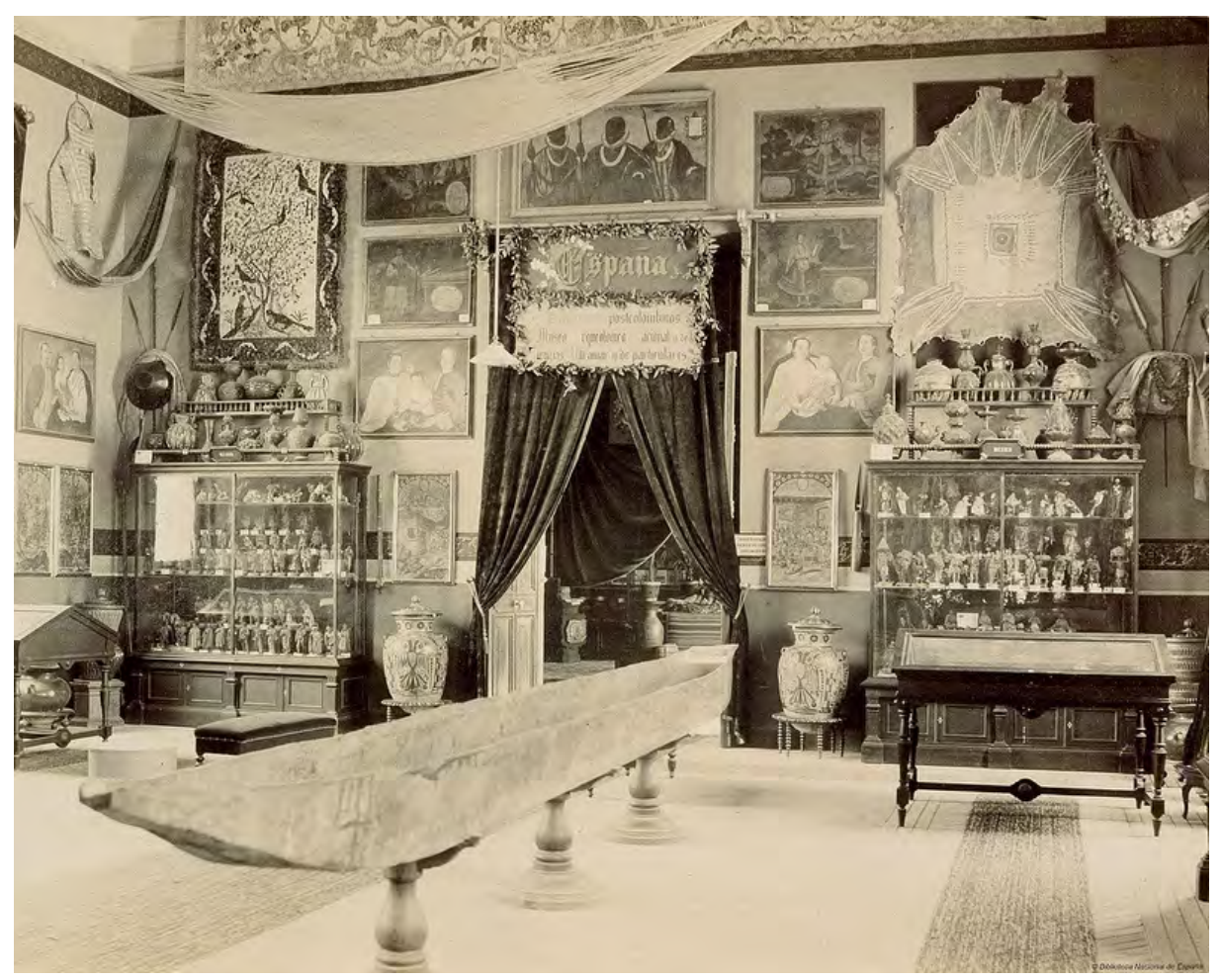

Imagen 1. Sección del montaje presentado por España.

Fuente: Biblioteca Nacional de España.https://www.flickr.com/photos bibliotecabne/7830097664/in/album-72157631174049584/ 
Esta sección en particular, presentaba objetos relacionados con la historia de España, más no aquellos vinculados con la época "precolombina"y colonial, los cuales ocuparon un sitio especial del que no quedaron constancias fotográficas.

La presentación española sobre objetos "precolombinos" fue extensa, tanto que ocupó la primera mitad del III tomo del catálogo (más mil páginas). No sólo presentó la colección del Museo Arqueológico Nacional, sino también objetos de "Las Antillas", México, Ecuador, Perú, "Nueva Granada" y otros "idolillos", códices, instrumentos musicales, exvotos, agoreros o adivinos, paleografía, objetos de culto, amuletos y una serie extraordinariamente amplia de objetos que hicieron su aparición mostrando el esplendor de un vasto territorio de antigua dominación española.

A las anteriores "nomenclaturas" se añaden otras, como: "Vasos representando cabezas humanas que demuestran las diferentes razas o variedades étnicas de los antiguos habitantes de Perú", o "vasos representando dos cabezas con la cara animada y por una risa burlona" (Sucesores de Rivadeneyra, 1893). La razón por la cual son presentados por España es presumiblemente, porque se encontraban en la colección del Museo Arqueológico Nacional (de España) o al menos bajo la custodia española, es decir, estos objetos se mostraban de manera independiente de los que presentaron las nuevas repúblicas latinoamericanas en el contexto de la exposición.

Sobre la presencia de Centroamérica en esta parte de la "colección española", hicieron su aparición dos categorías: "objetos indeterminados de Centro América" y "Códice maya", denominado Cortesiano, ejemplar rarísimo, así como su compañero el llamado Códice Troano, que con el de Dresde, son los únicos completos que se conocen de esta originalísima escritura de la América Central. El Cortesiano y el Troano se cree con fundamento que forman uno solo, divididos hace mucho tiempo (Sucesores de Rivadeneyra, 1893). La participación española también mostró objetos de la época "postcolombina": "Cuarenta y una cajas con medicamentos que el botánico don Hipólito Ruiz trajo de América en la expedición científica del reinado de Carlos III, así como un catálogo especial sobre los documentos históricos de indias del archivo de Simancas que contenían partidas referentes a Colón, cartas del Rey y la reina a Colón.

Desde el punto de vista de Centroamérica, llama la atención la presencia de un documento relacionado con el canal interoceánico, en el que se hace mención de la relación de Diego de Mercado, expedicionario vecino de Guatemala, quien indagó sobre la comunicación de los mares norte y sur por la laguna de Nicaragua y el golfo de Papagayo. Sobre el tema de las rutas comerciales, se presentó la concesión hecha a la compañía electoral Brandemburgo de América para 


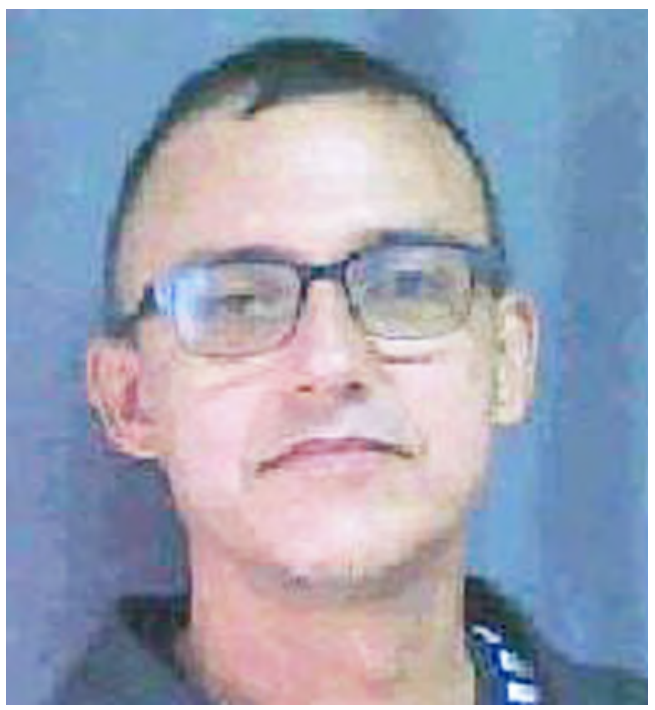

Guillermo Cubero Barrantes

realizar estudios de factibilidad para posibilitar el comercio con los españoles y los naturales del mar del Sur. La cantidad de documentos presentados en esta sección es amplísima, sin embargo, vale la pena destacar dos en relación al interés español por las riquezas de sus antiguas posesiones y lo relacionado al antiguo sueño español de encontrar "el dorado": la primera, Relación sobre oro y esmeraldas, además de Relación del descubrimiento del dorado, hecho por el gobernador d. Antonio Berrio (Sucesores de Rivadeneyra, 1893).

El catálogo que presenta la nación española también incluye una sección dedicada a presentar algunos objetos remitidos por el Capitán General de Filipinas, y que contiene entre otras cosas: una imagen de Nuestra Señora de Santa Clara, rosarios, monedas filipinas de plata y una antigua moneda árabe hispana del año 1492, "el año en que se descubrió América". También se presentaron documentos relacionados con las expresiones del cristianismo en la antigua civilización tagalog de Filipinas, así como de las labores de grupos religiosos como la Compañía de Jesús. La participación de Cuba, se hizo de manera especial, con el nombre de "El excelentísimo ayuntamiento de la Habana" el cual presentaba: en una magnifica caja de maderas finas del país, con el escudo de la ciudad en una de las tapas, y forrada interiormente de raso y peluche, los dos libros siguientes: "Documentos relativos a la traslación de los restos de Cristóbal Colón de la Catedral de Santo Domingo a la de la Habana, 1796" y “Álbum fotográfico, en folio apaisado, encuadernado en piel de Rusia con cantos de oro y cierres de plata, contienen las vistas siguientes: Castillo del morro, Entrada del puerto, vista panorámica de La Habana... panorama de 
La Habana tomada desde el castillo del príncipe... catedral de La Habana... altar mayor de la catedral donde se conservan los restos de Colón.....lápida en el sepulcro de Colón...el templete y busto de Colón... retrato de Cristóbal Colón...estatua de Colón...portada del cementerio de Colón...vista del cementerio de Colón...capilla del cementerio de Colón... Mercado de Colón... estatua de Colón en Cárdenas. Madrid 21 de octubre de 1892.

En el discurso articulado por España en el contexto de esta exposición, se pueden identificar varias particularidades. La primera tiene relación con su esfuerzo por presentarse con una colección tanto amplia como significativa, frente a los otros participantes, principalmente frente a Estados Unidos con el cual compite en el número de objetos. También llama la atención en cuanto a su tesón por presentar objetos "precolombinos", con lo cual buscaba rememorar su antiguo dominio sobre los territorios ahora independientes de América. Sus documentos también citan de manera sintomática todo lo relativo a "provanzas" y "testimonios" legitimadores de su dominio sobre estos territorios perdidos. También hacen su aparición numerosos documentos sobre La Luisiana, La Florida y Carolina del Sur con lo cual pone en evidencia otra tensión latente en su discurso de disputa de territorios con Estados Unidos. Los documentos relacionados con "el oro y las esmeraldas" y "El Dorado" revelan una antiguo interés por las riquezas americanas, ahora perdidas. Finalmente, es posible percibir una tensión en relación a Cuba y Filipinas, sus últimas dos posesiones importantes en ultramar. En relación con el "El excelentísimo ayuntamiento de la Habana" la tensión principal se nota en la manera en que se coloniza la isla, es decir, la forma en que de manera un poco arbitraria se le asocia con la persona de Cristóbal Colón.

Esta última tensión se hizo más evidente por el recurso retórico y la excesiva referencia al descubridor. Así como "coloniza" a Cuba, también "catoliza" a Filipinas. Dado el contexto histórico que vivía la España imperial de ese momento, son claras todas estas tensiones, en este momento la moral española estaba tan baja que sólo podía ser menor cuando terminara perdiendo a Cuba y Filipinas unos años más tarde.

\section{"Otros países"}

Por razones evidentemente retóricas, la participación de Colombia es presentada dentro del contexto de celebración de la figura de Cristóbal Colón, como una participación importante. Sin embargo, su presentación no mostró ningún aporte importante en relación a las otras participaciones, mostrando especialmente: "objetos etnológicos y arqueológicos, principalmente cerámica y relacionados con la cultura chibcha". Seguido de Colombia hizo su presentación el "Reino de Portugal". 
Los países "nórdicos" tienen una participación dispar. Los países escandinavos que se presentaron fueron: Suecia, Noruega y Dinamarca. También participó Alemania. El "Excmo. Sr Barón A. E. Nordenskiold" presentó los objetos de Suecia sin "introducción": mapas antiguos y fotos de buques y palacios de Estocolmo, también objetos etnográficos recabados por Carlos Bovallius, profesor agregado de la Universidad de Upsala.

Suecia también presenta objetos etnográficos procedentes de América, tal fue el caso de piezas de los indios de Talamanca en Costa Rica, colección hecha por Carlos Bovallius en 1882; de las islas de Zapatera y Ometepe, objetos de los Indios Mansos de Nicaragua; también artículos de la isla de Puerto Rico, así como una "reproducción hipotética de un templo azteca" y finalmente, un "modelo exacto de una galera marina sueca del siglo XVII, exhibida por el director de ingenieros de la Marina Real Sueca."

La participación de Noruega se limitó a presentar una reproducción exacta de un buque de los vikingos de época cercana al año $900 \mathrm{~d}$. C presentado por D. Gustavo Storm, profesor de la Universidad de Christiania. La participación de Dinamarca fue un poco más extensa pues "ilustra la vida de los esquimales, habitantes de Groenlandia, tierra septentrional de América, perteneciente a Dinamarca" así como el grado de "civilización" alcanzado por las poblaciones de este país en la edad media. Islandia forma parte del Reino de Dinamarca, mostrando también "publicaciones de la sociedad real de anticuarios del norte sobre el descubrimiento de Groenlandia" muestra objetos tanto de esta región (trajes de piel de foca), como de Islandia (ejemplares de algunos manuscritos antiguos islandeses y vaciado de una piedra con una inscripción en caracteres rúnicos).

La participación de los países escandinavos no deja de mostrar tensiones en cuanto a su discurso. La presentación de Carlos Bovalius de la Universidad de Upsala con objetos de Nicaragua y Costa Rica, deja entrever una nueva era en materia de imperialismo informal. Éste, con la investidura de la ciencia, adquirió derecho sobre los objetos de interés "antropológico" de cualquier parte del mundo. Sin embargo, las mayores tensiones se observan en la participación de Dinamarca, tanto por sus posesiones de Groenlandia como de Islandia, de las cuales presentó objetos en la exposición como suyas propias. También hay tensión discursiva en el contexto de la exposición en la frase "los habitantes de la isla de Islandia, que fueron los primeros exploradores del nuevo continente" y "sobre el descubrimiento de Groenlandia", pues ambos comentarios ponen en entredicho el mérito de Cristóbal Colón como descubridor de América. 
La participación de Alemania tuvo lugar con la colección del Dr. Edward Seler, subdirector del Real Museo Etnológico de Berlín con objetos arqueológicos de México, Guatemala, Perú, y Brasil, material que fue acompañado por publicaciones científicas sobre arqueología, etnología y temas afines a la cultura precolombina. Al igual que en el caso de Suecia, el enfoque científico permite una nueva forma de colonización, el interés científico permite el "acceso" a objetos de interés antropológico al que solamente se accedía en el pasado mediante el poder de la administración colonial.

Es realmente llamativa la manera en la que el discurso científico contribuye a articular una nueva forma de dominación mucho más sutil, pero sobre todo es importante cómo España quedó relegada ante este nuevo paradigma con el cual Alemania, Estados Unidos y Suecia, por citar tres ejemplos, controlaron una nueva forma de dominación colonial, con el aporte de las nuevas ciencias de la antropología y la arqueología.

\section{Centroamérica en la exposición del cuarto centenario}

Por Centroamérica participaron únicamente Guatemala, Nicaragua y Costa Rica. A pesar que el catálogo-inventario se encuentra destinado principalmente a desarrollar los temas de las exposiciones "americana" y la "española", el espacio cedido a las tres provincias centroamericanas no fue poco si se le compara con la participación de otras naciones. El esfuerzo de esta región por presentarse con lo mejor de sus colecciones y con un trabajo "teórico" que acompañara las mismas es destacable, pues sus presentaciones eran las más disciplinadas en cuanto al "rigor científico" exigido por los organizadores, un rigor que finalmente ni la misma delegación española respetó de manera fiel. Las presentaciones daban inicio con datos geográficos y estadísticos de los países, seguidos por datos historiográficos y cultura; para luego adentrarse en cuestiones más pragmáticas como el clima y la disponibilidad de recursos agrícolas, minerales y de diversa índole.

Guatemala destacó de manera particular su situación entre los océanos Pacífico y Atlántico y su istmo de Tehuantepec, así como su independencia de España en el año de 1821 (Imagen 2). La producción minera es importante, igual que la industria, la ganadería, la producción de cultivos como el café, la caña de azúcar, el banano y la vainilla, por mencionar algunos, tanto como la explotación maderera de especies endémicas como la caoba, el cedro, el ébano y el roble. La infraestructura del país es descrita con detalle, mencionando carreteras, puentes, canales, el ferrocarril y muelles (Sucesores de Rivadeneyra, 1893). 


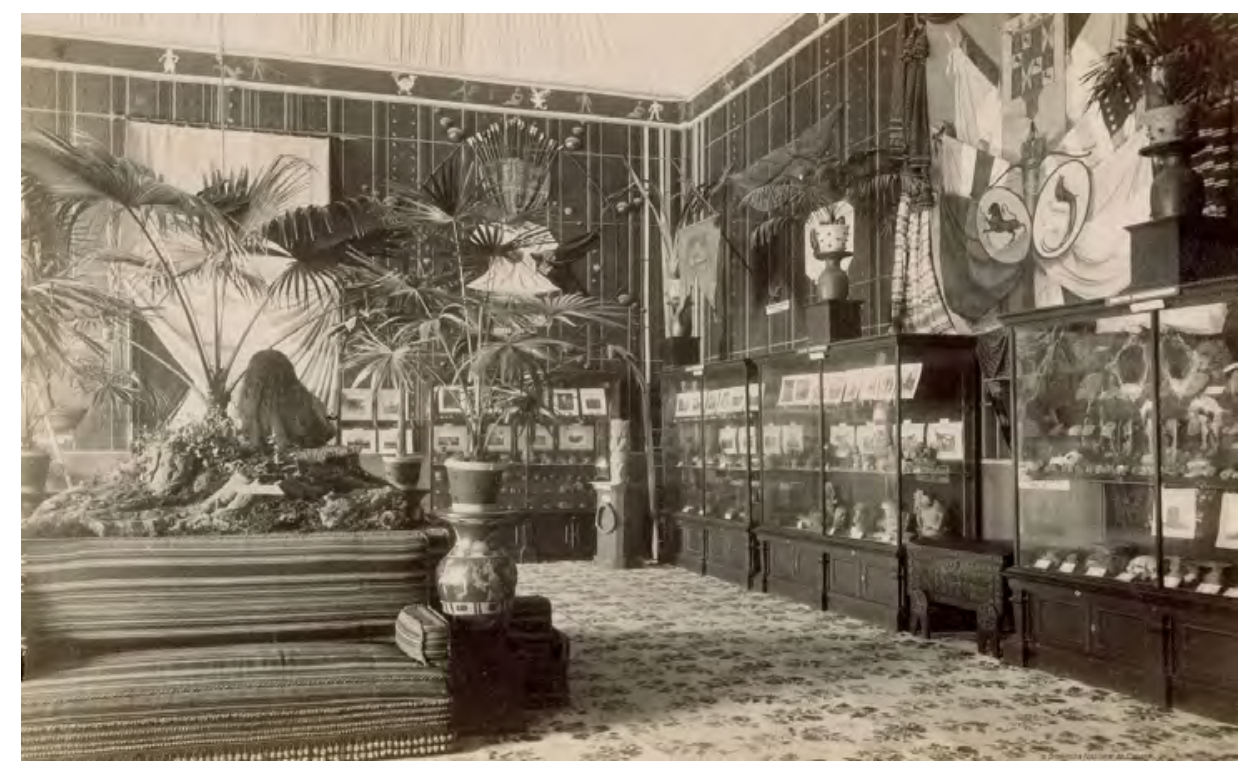

Imagen 2. Instalación de Guatemala para la Exposición Histórico- Americana de Madrid 1892. Fuente: Biblioteca Nacional de España.

El texto evoluciona sin sobresaltos importantes hasta que se hizo referencia al tema indígena. El componente indígena de su población - dos terceras partes más una tercera parte de ladinos - se constituye en un elemento de tensión en el marco de una cultura neocolonial europea fuertemente racista del siglo XIX. En el catálogo de Guatemala, el pasado precolombino se encuentra asociado al reino náhuatl de los Cachiqueles el cual le dio nombre al país (quauhtemalan). Al hacer referencia al idioma se percibe una serie de tensiones importantes, pues en ningún momento se indica cual es la lengua más hablada, solo se señala que el idioma nacional es el castellano, y por otro lado "los indios, aunque casi todos hablan el español, conservan entre sí el uso de sus lenguas primitivas, como son el maya, el quiché, cachiquel, zathil, etc, etc" [sic] (Sucesores de Rivadeneyra, 1893, p. 13).

Se agrega que también se han generalizado mucho el conocimiento del inglés y el francés. Una tensión puede percibirse en el adjetivo primitivas para referirse a las lenguas originarias, y por otro lado, el uso de etc, etc, que sugiere la invisibilización de algunas lenguas, por su desconocimiento o porque no son consideradas importantes o por cualquier otro motivo. En cuanto a lo generalizado del inglés y el francés, el autor no explica si se refiere a toda la población o si se refiere únicamente a la población ladina, excluyendo con esto a los grupos indígenas. También llama la atención la desaparición de la categoría blancos puros, hijos de españoles que hacían su aparición en descripciones anteriores. 
La religión se suma a las tensiones raciales, pues se indica que la Constitución guatemalteca permite el ejercicio libre de culto religioso, sin embargo, este libre ejercicio no podrá extenderse hasta ejecutar actos subversivos o prácticas incompatibles con la paz y el orden público, ni da derecho para oponerse al cumplimiento de las obligaciones civiles o políticas. Por otro lado la religión dominante entre los naturales es la católica, pero entre los extranjeros residentes hay muchos protestantes de diversas sectas y algunos judíos.

También destaca la presencia de la masonería pues hay logias escocesas en Quetzaltenango, Guatemala y Retalhuleu y en la capital reside el gobierno de la Masonería del Centro de América. En conclusión, el libre ejercicio de la religión solo aplica para las religiones europeas, en tanto que las prácticas religiosas de los naturales se encuentran obligadamente circunscritas al dominio de la religión católica, cualquier desviación de esta norma podría ser interpretada como acto subversivo.

El inventario continúa proporcionando datos sobre la civilidad del país, su régimen "democrático, republicano y representativo", con división de poderes legislativo, el ejecutivo y el judicial, así como la instrucción pública, las bibliotecas, los teatros, alumbrado, hipódromos, policía, hospitales para atender diversas enfermedades y poblaciones (el hospital militar, el de venéreos, el de la prisión de mujeres, el asilo de dementes, el asilo de elefanciacios, entre otros). Poseen además periódicos y sistema de medidas y monedas. La delegación de Guatemala presentó manuscritos históricos como el Isagoge apologético general de las indias, Historia de la provincia de San Vicente Ferrer de Guatemala y Chiapa [sic] y fotografías de las actas del cabildo de la primera ciudad de Guatemala.

Nicaragua es mostrada por una delegación de tres comisionados, que presentan el catálogo, destacando a Rubén Darío como comisionado literato. El documento subraya la civilidad nicaragüense, reflejada en su gobierno republicano y su religión católica, apostólica y romana con un obispado en la ciudad de León. Tierra feraz de lagos y volcanes, se caracteriza por la riqueza no solo agrícola y ganadera, sino también minera de su suelo, la población blanca, mestiza e indígena. Con respecto a la colección exhibida, un total de 1201 objetos, todos precolombinos, se afirma que casi todo es barro cocido además se utiliza la caracterización de policromos para referirse a la pintura de muchos platos, así como las cazuelas, ollas y otros productos.

Después de proporcionar información geográfica, estadística y del clima, como preámbulo, el texto se dirige a describir lo relacionado con el tránsito interoceánico: 
Nicaragua tiene dos puertos que dan a ambos océanos, 300 millas de al lado del atlántico y 200 del pacifico. Hay ríos caudalosos, el más importante es el del río San Juan, que desemboca en el Atlántico y une este océano con el gran lago de Nicaragua (...) el ferrocarril de Nicaragua es uno de los mejores de la América Central, el viajero puede pasar de un océano a otro por medio de la vía férrea (...) el canal interoceánico está en vías de llevarse a cabo, y es de esperar su realización, tomando en cuenta que está en tal obra interesada una importante compañía norteamericana.

En relación a la participación de Nicaragua, la tensión evidente se encuentra en su interés por el canal interocéanico, así que esta tensión estará presente en casi todas las exposiciones internacionales cuando se menciona el tema centroamericano, siendo en el caso de Nicaragua en el que se evidencia una tensión mayor al presentarse como un territorio apto para el gran proyecto del canal. Llama la atención que al mencionar el Río San Juan, en ningún momento señala que sea limítrofe con Costa Rica, lo cual añade, por ocultación cierta tensión al texto.

Como ya se ha señalado antes, las presentaciones centroamericanas se rigen cuidadosamente por un esquema preestablecido que detalla la ubicación del país, superficie, clima, tipo de gobierno, las principales ciudades, la agricultura, el comercio, la economía y las vías de comunicación. En el caso de Costa Rica, este preámbulo es seguido por una reseña histórica que cuenta de la llegada de Colón para continuar con la vida colonial y finalmente describir a los pueblos indígenas que ocuparon el territorio.

El título del inventario, Catálogo general de las antigüedades indígenas de la República de Costa Rica, llama la atención por la omisión del calificativo precolombino, sugerido por las autoridades españolas. La colección está compuesta por figuras de oro, jades (o piedras verdes) y piezas cerámicas, pertenecientes a las colecciones del Obispo Thiel, a doña Dolores Troyo, a Juan Matarrita y a don Julio Orellano quien exhibe "un muñequito pequeño, oxidado, y un cascabel, también carcomido". (Sucesores de Rivadeneyra, 1893, p. 34).

La poca atención que se pone al valor de los objetos presentados queda en evidencia por el siguiente comentario: también exhibe Costa Rica cerca de 1.000 objetos extraídos a fines del año pasado del cementerio del Guayabo, (...) pero omitimos su especificación por ser todos los objetos más o menos semejantes a los anteriormente citados, de oro, cobre, piedra y arcilla quemada. Esta falta de especificación es un indicador de manejo poco cuidadoso de la colección, y el peligro de su desaparición por falta de controles de inventario. 
No está demás señalar que la reacción del público europeo ante estos objetos ha sido señalada como ambivalent, pues se muestran tanto despectivos como fascinados por las otras culturas, su gente y su producción material. En este contexto es posible que muchos de estos objetos sin especificar terminaran en manos de terceros.

Además de las colecciones arqueológicas, hay en la sección costarriqueña una gran cantidad de ejemplares etnológicos como arcos y flechas, bastones, cerbatanas, tejidos, plumeros, collares de dientes, redes, hamacas, cuerdas de pescar, tambores, etc. Todo procedente de las actuales tribus de indios que en pequeñas agrupaciones, se hallan esparcidos al Norte y Sur de aquella República, así como una vista general del cementerio de Turrialba, que tanta luz ha traído a la historia precolombina de aquella parte de América Central.

El texto referido a la sección costarriqueña no da muestras de grandes tensiones, y es posible que éstas no se encuentren en lo dicho, sino más bien en lo no dicho. El Canal Interoceánico afectaba los intereses del país tanto por el norte como por el sur y la presión internacional era considerable, sin embargo, sobre este particular, el texto no dejó entrever nada. Las tensiones raciales, podían ser, sino iguales, por lo menos similares a las que se verían en Guatemala y a otros países centroamericanos, al igual que la invisibilización de los grupos indígenas y la imposición de un modelo liberal eurocéntrico era tan intolerante, o más, que en los otros escenarios del istmo. Las tensiones entre Iglesia y Estado se encontraban también en el horizonte, sin embargo, ante todos estos fantasmas, la legendaria postura costarricense del alejamiento diplomático de las tensiones, no dejaban entrever ninguna en el texto, esta es quizás la mayor tensión.

\section{Discurso de Eugenio Texeira en el "Cuarto Centenario del descubrimiento de América"}

Además del catálogo-inventario de la exposición del IV Centenario, el único documento, localizado en la Ibero- Amerikanisches Institut Bibliotek de Berlín, es el El discurso de Eugenio Texeira (1892), pronunciado en la inauguración de la exposición universal de Bellas Artes en el IV Centenario. Aunque ningún país centroamericano tuvo participación en esta sección, es importante tener en cuenta, al menos en lo general, la visión de Texeira como participante en la actividad fungiendo de delegado de un país americano - Brasil - en dicha exposición universal. 


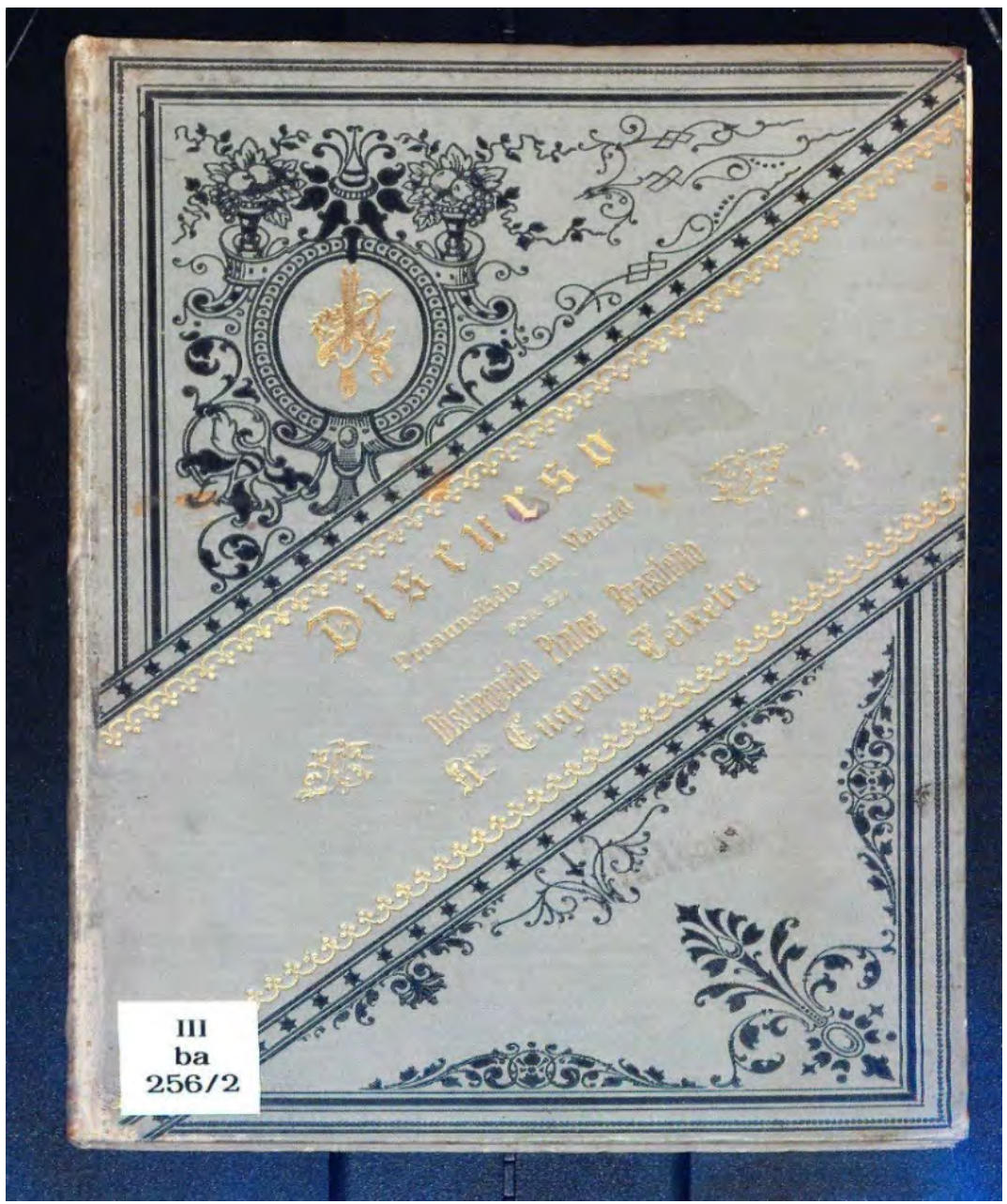

Imagen 3. Portada del Discurso de Eugenio Texeira. Fuente: Ibero Americkanisches Bibliotek.

El boletín consultado, cuya fecha de impresión es del 15 de diciembre de 1892, es un pequeño documento lujosamente impreso (Imagen 3), que es prologado, compuesto de una carátula barroca, con la efigie del pintor a la manera de una moneda y su firma, así como una magnífica reproducción litográfica de la pintura presentada por el autor en la Exposición del Cuarto Centenario llamada "La primera comunión en América" (Imagen 4). La pintura requeriría un análisis semiótico por aparte, pero en resumen, presenta una escena eucarística a la orilla del mar en medio de un oscuro y frondoso bosque tropical cuya figura principal es el comulgante Colón, detrás del cual aparece toda la comitiva de conquistadores reclinada en posición devota. 
El texto es muy complaciente e insiste en rendirle pleitesía a la audiencia, sobre todo porque esta audiencia incluye al Rey de España. El texto construye discursivamente una serie de retratos o descripciones que apuntalan vasallaje, rebeldía, capitulaciones y acuerdos. El autor se definía a sí mismo como haciendo fuerzas de mis flaquezas, débil, disminuido (...) hijo allende del mar, mientras declaraba que hablaba en nombre de los americanos. Colón es retratado entre tanto como astro sublime, inmortal, intrépido Genovés, amparado por la Corona de España. En este punto se hace presente una pequeña tensión en el intrépido Genovés, pues una de las discusiones candentes en el contexto de las celebraciones es la nacionalidad no española de Colón y por lo tanto la deslegitimación del reclamo español del descubrimiento.

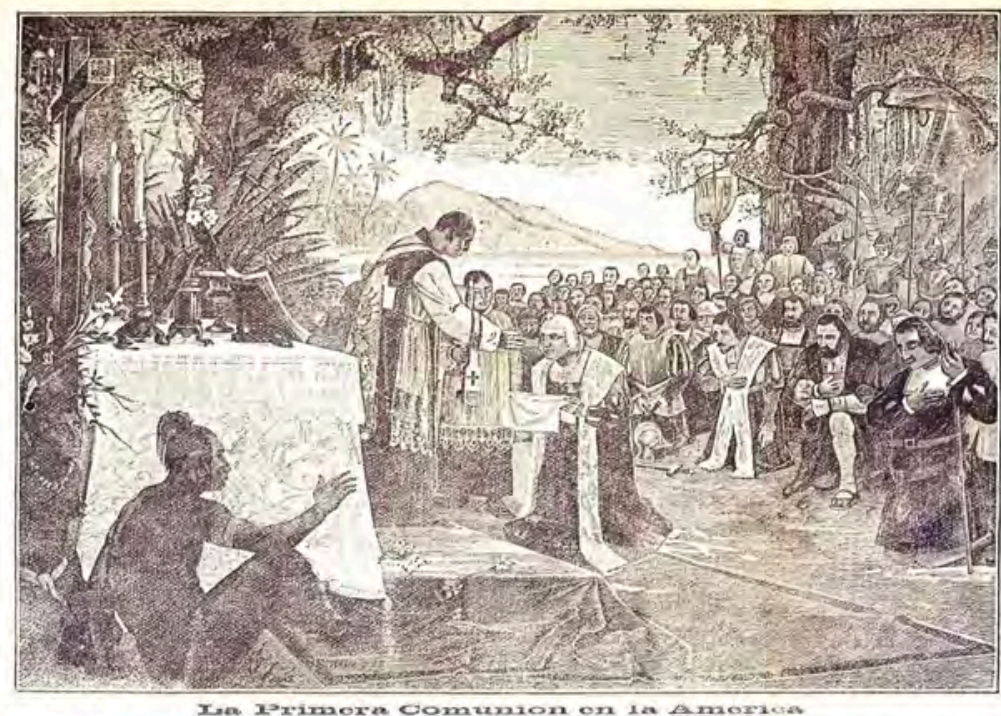

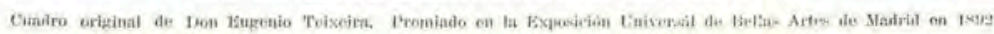
Jupmata Thierral

twing sirmplares

Imagen 4. Reproducción de la pintura La Primera Comunión en América. Fuente: Discurso de Eugenio Texeira. Ibero Americkanisches Bibliotek.

El texto avanza, por momentos, con una retórica casi ilegible debido a la extrema estilización: el cuerpo es cautivo; pero acionando [sic] en la forma pasiva, es su instrumento en el mundo físico. La cultura eurocéntrica se condensa en la figura de sus genios: un Colón, un Franklin, un Gutenberg, un Newton, un Murillo, un Mozart o un Verdi, como tantos faros en las generaciones en el mar de la existencia en ondas sucesivas en la popularidad envoltoria de los cosmos infinitos. 
La cultura europea se ve no sólo caracterizada sino también legitimada en cuanto a su acción colonialista: atraviesan los mares, unen los continentes por los hilos eléctricos transmitiendo los pensamientos. Desvían los ríos, estancan los pantanos, rasgan los ismos [sic], sondean y roban de las entrañas oceánicas sus más recónditos tesoros de perlas y corales. Este estilo empalagoso, esconde y revela, sin embargo, pequeñas tensiones, pues la acción colonialista eurocéntrica desvía, rasga y roba.

América es descrita como el Edén soñado, la América del presente y la América del porvenir, mientras el descubrimiento no se trata solamente de un acontecimiento geográfico sino y sobre todo de la introducción benéfica del Cristianismo en un continente salvaje que trajo para la falange de fieles millares de paganos por el agua bautismal al seno de la civilización. En este parte del texto, el autor utiliza en el mismo párrafo dos importantes elementos presentes en la tensión del discurso colonialista: salvaje y civilización.

La noción de salvaje asimilado a la figura de un monstruo, hace de nuevo su aparición por oposición a la cultura eurocéntrica: quien no se sentirá orgulloso admirando las notabilísimas telas de Murillo, Rubens o Velásquez? (...) solo un monstruo o un salvaje, permanecerá indiferente ante esas divinas manifestaciones, en presencia de las cuales se desprenden sentimientos inspirados en las emociones de la naturaleza, sin embargo, el autor tiene dificultades para posicionar a la naturaleza del lado del salvaje, esta tensión textual es uno de los aspectos más llamativos del discurso de Texeira.

El cristianismo, es para Texeira, la principal fuente civilizadora del mundo salvaje de América, pues en el inventario de la humanidad hay dos grandes legados: el Calvario y la América, pero también la estética de occidente inspirada en Grecia cuyo fondo se nivela con la forma, mientras en Oriente el fondo se impone a la forma.

Cristianismo y naturaleza, encuentran en el discurso de Texeira una extraña combinación, que también aparece en su cuadro de la exposición: Una eucaristía en medio de la selva. La naturaleza hace su aparición en un párrafo y en otro, siempre en su versión de lo sublime: en la selva transformando nuestras delicias en armónicos oleages [sic], llevan consigo el fastuoso cortejo de todos los murmullos de la naturaleza (...) en fin es el Señor de la naturaleza entera la cual es sólo por él comprendida e interpretada. La inusitada relación que encuentra Texeira entre Cristianismo y naturaleza, pero no entre selva y salvaje es una de las más interesantes tensiones del texto, una señal de clara contradicción y de ambivalencia producida por el alejamiento de un hijo allende del mar. 
El texto termina, haciendo referencia a Colón quien apunta hacia América, y dice lo siguiente: de aquel que apuntando para el Occidente, dice a la humanidad, para después morir: ¡HE AHÍ UN NUEVO MUNDO, YO TE LO OFREZCO! Y concluye con una tensión interesante: declara en forma directa y visual la ubicación de Occidente, el cual geográficamente se ubica no en Europa sino en América

Es posible, y no hay razón para no imaginarlo, que la extrema oscuridad retórica del texto de Texeira, que lo hace a veces casi incomprensible, no se deba solamente a una cuestión de estilo, sino pragmática. En el contexto de las celebraciones del IV Centenario las polémicas y las discusiones van y vienen, la presencia del Rey de España entre otras figuras importantes, agregan tensión al evento y a sus discursos. El texto de Texeira se atreve a ir más allá en más de una ocasión, es un texto laudatorio pero también crítico, en ocasiones pareciera mostrarse temeroso, contradictorio.

Sin embargo, lo más destacable de este texto es su validez en cuanto a la presencia de las oposiciones semióticas propuestas por Soussa Santos en relación a lógica discursiva colonialista. Las oposiciones: salvaje-civilizado, occidente-oriente, y naturaleza-cultura hacen su aparición de manera clarísima, como si el texto hubiera sido redactado tratando de seguir la lógica de dichas oposiciones. Por otro lado, llama la atención la ambivalenciadel texto, pues el sujeto que articuló el discurso se identificaba como americano, pero también como eurocentrado, lo cual evidencia una tensión.

Occidente y no occidente se presentan de manera compleja. La línea divisoria se rompe y se evidencia tanto la ambivalencia como la tensión. La naturaleza y la cultura no muestran para el autor ninguna oposición, pues aparecen extrañamente fusionadas por su espíritu religioso. Es como si el discurso colonialista se encontrara prudentemente matizado, alabando la figura de Colón, y la preeminencia de la cultura europea, pero señalando veladamente los abusos coloniales. En fin, el discurso se podría sintetizar como una tensión particular entre lo salvaje, la civilización occidental y la admiración por la exuberancia de la naturaleza.

\section{La feria colombiana de Chicago de 1893}

En la visita realizada a la Exposición de París de 1889, los círculos industriales estadounidenses pudieron constatar el éxito logrado por Francia en la dinamización de su economía a partir de estos eventos, y decidieron realizar su propia versión americana de exposición universal. Para este fin se sacó partido de la celebración del IV centenario del descubrimiento de América que tendría lugar tres años después. Sin embargo, debido a que España celebraría su propia 
exposición universal de cuarto centenario en 1892, Estados Unidos esperaría estratégicamente al siguiente año, 1893, para la celebración de su magno evento al cual se le llamaría Feria Mundial Colombina en honor a la figura de Cristóbal Colón.

Antes de esta exposición mundial, los Estados Unidos ya había celebrado importantes exposiciones de carácter nacional como la de Nueva York en 1883, la de Manchester en 1867 y la Centennial exhibition en Filadelfia en 1876, en conmemoración de la Independencia de las 13 colonias y en el contexto de la cual Francia dona a la ciudad de Nueva York, la Estatua de la Libertad.

El éxito logrado por París en sus exposiciones universales fue decisivo para lanzarse a la tarea de realizar una versión en América. Se había observado que, a pesar del déficit económico mostrado en algunas, Francia experimentó con cada una de ellas una gran prosperidad económica debido a los acuerdos comerciales originados en el contexto de las mismas. Es por esta razón, que la exposición de 1889 en París se estudió cuidadosamente, teniendo en cuenta sus gastos, su emplazamiento, sus estrategias y su visitación, para sacar el mayor provecho posible en la nueva versión americana.

La escogencia de la ciudad anfitriona para esta feria mundial, fue una preocupación inmediata y después de una pugna entre Nueva York, Chicago, Washington y Saint Louis, Chicago tomó la delantera al aportar los cinco millones de dólares que se necesitaban para ganar el puesto, en una votación nacional en la que fue elegida por 157 votos. En 1890, se presentó el proyecto para su organización de la exposición, se aprobó en las dos Cámaras de representantes y el presidente de la República publicó la proclamación, invitando a touts les nations de la terre para la participación en el evento que ocuparía la premiere place dans l'histoire du monde.Cabe destacar que una de las mayores diferencias con sus antecesoras europeas, es que la Feria Mundial de Chicago fue financiada, no por la participación de la industria y la empresa privada, sino directamente por el Gobierno de los Estados Unidos. En su financiamiento participaron el Departamento del Tesoro, el Instituto Smithsoniano y el Departamento del Interior.

Entre los documentos que se conservan sobre la exposición, los más significativos son: World's Columbian Exposition, Chicago, 1893(denominada en adelante, World's) una especie de memoria, que en la práctica funcionó como catálogo razonado de la exposición, editado por la Congress Library; el otro documento es la llamada Guide General de 1893, editada por la Societé des Publications Françaises, de Montreal. 
Por estar escrito en inglés y editado directamente por el Gobierno Federal de los Estados Unidos, World's puede ser considerado como el documento más representativo de la exposición, y se destaca por ofrecer abundante información sobre los apartados de la exposición, los países participantes, la participación hispanoamericana, el interés por destacar la hegemonía mundial de los Estados Unidos, la importancia de su arquitectura y de manera singular, la figura de la mujer en el nuevo modelo de mundo que aspira al progreso y la civilización.

La Guide, por su lado, dedicó buena parte de su discurso a la historia de la ciudad de Chicago, y a la explicación de todo el proceso de realización de la exposición, desde su conceptualización durante la visita a París en 1889, hasta la construcción de la ciudad jardín a la orilla del Lago Chicago. Este documento puso énfasis en su gusto por lo europeo en la feria y en toda la extensión de su texto no aparece ninguna referencia a Centroamérica, a pesar de su entusiasta participación. Sobre este documento, uno de los poquísimos que se conservan de la Exposición Colombina de Chicago de 1893, llama la atención que esté escrito en francés y no en inglés, el idioma oficial de la feria.

\section{A imagen y semejanza de Europa}

La exposición de Chicago no difirió mucho en cuanto a procesos de clasificación, caracterización, desarrollo de nomenclaturas y ordenamiento de los temas, en relación a sus predecesoras europeas, de hecho, se había tenido en cuenta una minuciosa observación de la de 1889 en París, para garantizar el éxito de la versión americana. Las industrias aparecieron con un protagonismo central y se desglosaron en sus diversas ramas, como la industria de la guerra, la textil, la imprenta y la manufactura en hierro y madera entre muchas otras. Artículos como las estufas, la relojería, las máquinas de escribir y el papel tapiz, contaban cada una de ellas con su propio pabellón nacional.

A diferencia de las exposiciones europeas, en las cuales la empresa privada patrocinó los gastos de las exposiciones, en Chicago todo corrió por cuenta del gobierno, mientras que las industrias y las empresas tuvieron la oportunidad de expandir sus negocios completamente bajo el patrocinio del Estado. Esta característica se constituyó en una de las más notables diferencias entre los catálogos europeos y el de Chicago: la total ausencia de publicidad de parte de los empresas patrocinadoras; otra variante interesante la constituyó el hecho de que las empresas construyeron sus propios edificios dentro de la exposición, tal es el caso de compañías como Anderson Piano Company o la Standard Furniture Company.

Por detrás de la industria, la minería y la horticultura compartieron su lugar de privilegio en la muestra, luego le siguieron los temas relacionados con la historia 
natural, como la ornitología y finalmente, "las plantas de trópico americano" bajo un domo de cristal, como elemento exótico. Como era costumbre en este tipo de eventos, los organizadores hicieron un esfuerzo por mostrar adelanto en la técnica, esta era la razón por la cual en el catálogo se utilizó de manera profusa la fotografía, la cual sustituyó casi en su totalidad a la ilustración impresa, usada en los catálogos europeos; la fotografía trasladada a la imprenta, se dedicó sobre todo a retratar los edificios construidos de manera expresa para la exposición, de tal manera que arquitectura y técnica fotográfica se presentaron como algunos de los grandes adelantos exhibidos en la muestra. Por primera vez, se presentó a cada Estado del país anfitrión por aparte: Pensilvania Exhibition y Ohio Exhibition, Michigan section, Iowa exhibit, States United Section. El tamaño de Estados Unidos es tal, que requirió mucho espacio en la exhibición: hubo un salón para cada estado y uno para los Estados Unidos en su conjunto.

El documento además de estar escrito en francés, mostraba una predilección por mostrar la imitación de que fue objeto la exposición universal de París de 1889 en la Feria Mundial de Chicago; según Guide, la exposición americana ocupó, de manera similar a la de París, una superficie de 200 acres, mostró 55,000 objetos y fue visitada por 22, 149, 353 personas en los 185 días que permaneció abierta (1893). El documento abunda en la descripción de los hoteles, transporte, hospedaje, ópera, teatro, diversiones y facilidades en general. Aunque la cantidad de teatros y otros espectáculos era impresionante, difería a la de París en la naturaleza de los entretenimientos, mucho más dirigidos a la familia que a "les plaisirs", tan característicos de la capital francesa. De manera similar a la exposición parisina, Chicago pasó a la historia por su elemento central, en la de París: la Torre Eiffel, en Chicago: su famosa "Chicago Wheel", que se convirtió en el centro de las ferias de juegos mecánicos alrededor de todo el mundo (Imagen 4).

La visita a la exposición contaba con un itinerario fijo, lo cual sugiere que el tránsito por la exhibición estaba fuertemente regulado. Los principales espacios eran: el corazón central, el peristilo, una sala de música, el muelle, el Convento de la Rábida y la lechería entre otros. Más que en las exhibiciones anteriores, la de Chicago se caracterizó por un excesivo control, la sistematicidad y el adoctrinamiento en materia de comportamiento socialmente ajustado a las normas, las leyes y la moral, los entretenimientos son de sana diversión, en contraposición a París de 1889, mucho más relajado.

Un espacio interesante fue la lechería modelo, la cual daba una idea bastante clara de la evolución conceptual que experimentaron las exhibiciones universales a lo largo del siglo XIX, las cuales pasaron desde sus primeras versiones puramente artísticas, hasta irse adaptando cada vez más a las necesidades del comercio y del mercado, tanto que la exposición de Chicago fue presentada 
en sus documentos oficiales como fair en lugar de Exposición. La lechería modelo de Chicago, por ejemplo, en una exposición financiada y gestionada enteramente por el Estado, mostrando una actividad productiva, con todos sus procesos, refrigeradoras, cámaras frigoríficas para conservar los productos y la oportunidad de su degustación por parte de los visitantes.

Cabe destacar que, de manera curiosa, la Exposición de Guatemala de 1897 regalaba barquillos de helado y champagne, para la degustación de los visitantes, en una clara emulación de las anteriores exhibiciones universales.

De manera similar en la que la exposición de París de 1889 presentó a la cuidad como el centro de la vida cultural del mundo, la exposición de Chicago buscó posicionar al país anfitrión como la primera potencia mundial en los ámbitos de la política y de la economía. En algunos apartados se insistía en la intención hegemónica del país y especialmente de su ciudad, que a partir de la exposición tuvieron un lugar de honor en l'histoire du commerce universal debido a la importancia de Chicago por sa merveilleuse richesse comercial.

Otro aspecto que llamó la atención del mundo en su visita a la exposición de Chicago, fue su influencia en la arquitectura mundial del siglo XX. La invitación a importantes arquitectos de todo el país permitió la creación de un estilo elitista y clásico típico de las les villes américaines, especialmente inspirado en la arquitectura típica de la costa este del país. Para la exposición se construyeron de exprofeso bancos, bibliotecas, iglesias, hospitales, morgue y cementerio. Por otro lado, la creación de múltiples parques, paseos, plazas y bulevares, cuya abundancia de vegetación, sombra, flores, y enzacatados le dio a la ciudad el apodo de la ciudad jardín. Llama la atención que a pesar de la importancia que tuvo la participación extranjera en la creación de edificios para la exposición colombina, como fue el caso de México o China, que luego inspiraría a arquitectos americanos para sus innovaciones en el siglo XX, el documento de la Guide no hace ninguna referencia a esta participación y su aporte.

La guía general editada en francés, presentaba a la ciudad de Chicago como la "Reine de l' Ouest", mientras se destacaban todos los atributos por los cuales fue la elegida para la Feria Mundial, entre otros, por el dinamismo de su crecimiento, su posición geográfica central en el norte del país, lo que favorecía el intercambio entre el este y el oeste, su clima templado y sus condiciones de salubridad, ${ }^{1}$ sistema público higiénico, administración con un aparato fuerte de represión policial, para mantener un nivel bajo de delincuencia y un bajo nivel de mortalidad.

1 Estudios antropológicos de la época señalan como "clima sano" alrededor del mundo el clima del norte de USA y Europa por oposición a los climas "insalubres" de las regiones tropicales. 
Esta ciudad considerada en el catálogo como la plus fameuses de l'ancien et du nouveau monde con una población riche et orgueilleuse, se levanta a orillas del Lago Chicago, posición que fue aprovechada por los diseñadores de la exposición para dar un aire veneciano a la muestra, de tal manera que el efecto general, del paisaje y la arquitectura debían dar la sensación de encontrarse en una especie de Europa renovada y actualizada, es decir, el nuevo centro de Occidente. Parte de los atractivos de la Feria, eran los viajes en góndola, guiadas por sesenta gondoliers ataviados con sus atuendos de colores brillantes al estilo del siglo XIV, traídos expresamente desde Venecia, para darle un toque de romance a las tardes de la exposición.

En materia de arte y cultura, el eurocentrismo no dejaba duda, en todas las formas de expresión artística, denominadas en los documentos como artes liberales y que concentraron la música, piano, órgano, fotografía, exhibición de educación católica la música mencionada como preferente era la coral e instrumental y podían apreciarse en la Sección alemana y sección francesa. En cuanto a las artes plásticas, se mostró una afanosa imitación de las tendencias europeas más conservadoras, generalmente realismo y naturalismo y algunos guiños con el impresionismo francés. Algunos eran prácticamente réplicas de obras famosas en Europa con algunos cambios en la perspectiva o la ejecución.

El proyecto de la exposición encargó de manera especial la elaboración de estatuas de personajes célebres para adornar sus abundantes parques y jardines. Debido a la celebración colombina, esculturas de Cristóbal Colón fueron colocadas en compañía de figuras de Linneo, Frederick von Shiller y La Salle, con lo que se establece mediante una retórica artística a la estética, religión y ciencia instrumental europeas como modelo ideal de lo civilizado. Así mismo, se decoró la ciudad con réplicas estatuarias del César Augusto del Vaticano, de Mozart niño, entre otras. Estatuaria no retratística como la ciencia elaborada en un estilo idéntico a la estatua de la Libertad en Nueva York.

La manera en que fueron citados los países participantes en The World's Columbian Exposition, Chicago revela una fuerte estrategia diplomática, mientras se advierte un trato preferente en el discurso hacia los países europeos, los cuales fueron mencionados uno por uno, haciendo una breve referencia, siempre aduladora, sobre su condición de país y su participación: the unapproachable beauty in the Athens of Pericles. De oriente se menciona a Turquía (se hace énfasis en su Mohamedan religion), mientras que la cultura japonesa es presentada con un trato especial de manera similar a los países europeos. Un caso notorio, es la participación China, la cual se encontraba en medio de un conflicto en relación a su participación en la Feria, sin embargo, se destaca the enchantment...of the oriental tales. El texto se caracterizó por el énfasis que puso en la condición de universalidad del evento, al destacar la 
participación casi absoluta de todos los países del orbe: from Dan to Beersheva, from New York to París, from Iceland to Egipt.

\section{Racismo y eurocentrismo en el Chicago de 1893}

La Guide proporciona información abundante sobre las particularidades, curiosidades y los antecedentes de la exposición de Chicago, no sin dejar de entrever el etno-eurocentrismo característico de las exposiciones universales del siglo XIX, pues da inicio, haciendo un recuento de nacionalidades que conformaban el amplio abanico de la población propia de Chicago. La lista de tipos de habitantes se presenta a nivel descendente de acuerdo al número, así les americains, que son el mayor número, encabeza la lista, es seguida por múltiples nacionalidades europeas: allemands, bohemiens o polonais, estos se citan en orden descendente de acuerdo a su número en la comunidad.

Sin embargo la citación de habitantes de origen no europeo crea muchas dudas, pues, además de ser citados en una posición inferior, después de los europeos, se confunden las nociones de nacionalidad con el de raza y etnia. La primera confusión se suscita en relación al grupo de les indiens que aparecen en número inusitadamente bajo y no hay manera de saber si se refiere a hindúes o indígenas americanos; el segundo grupo que llama la atención son les mongols, igualmente, es difícil suponer si en realidad se refiere a personas originarias de Mongolia o es una manera de designar de manera genérica a personas provenientes de Asia o que comparten rasgos similares con esa población. El siguiente grupo está relacionado con los provenientes des Antilles, que hace suponer que se refiere a habitantes de la América Central insular, pero tampoco es claro, dada la variedad de poblaciones de esta región del continente; y finalmente, pero no menos importante, es la citación de les negres que en número superan al resto de los inmigrantes citados en la tabla pero son, sintomáticamente citados al extremo inferior de la misma.

Además del racismo y etnocentrismo implícitos en la conceptualización y la sintaxis de esta tabla, se suma una lógica eurocéntrica en la ubicación de Chicago en el mundo, pues se elabora una tabla de distancias de Chicago con el resto del mundo. Este resto del mundo lo componen en primer lugar, ciudades estadounidenses como Boston, Nueva York, Washington o San Francisco. Seguidas de las ciudades de la unión aparecen ciudades centroeuropeas como Liverpool, La Havre, Edimburgo o San Petersburgo; pasando, obviamente por París, Roma, Berlín y Madrid, y con estas últimas, se completa la ubicación de Chicago en el mundo el cual pareciera resumirse a un mundo estrictamente Atlántico norte y el resto del mundo no aparece, con lo cual se convierten en como si fueran inexistentes. 
Llama la atención el énfasis que el documento pone en el control social, pues se cita en diversos apartados la importancia de las prisiones y del control policial, entre otras instituciones represivas. El documento hace alarde de la capacidad de represión de la policía, mientras hace referencia a las 70,550 arrestations que tuvieron lugar en 1891. También llama la atención el imaginario invocado, pues se le da gran relevancia a la figura policial la cual se encuentra representada en una escultura conmemorativa de una represión policial, citada como hecho histórico, y se realiza una escultura de un policía como imagen icónica de la ciudad.

\section{Occidente se desplaza hacia el occidente}

Occidente, más que un lugar geográfico es un lugar simbólico (Said, 2002) identificado principalmente con Europa del oeste, sin embargo, el centro de este lugar simbólico experimentó un notable desplazamiento desde Europa occidental hacia la nueva potencia del siglo XX, los Estados Unidos y es básicamente ésta la imagen que intentó posicionar la exposición de Chicago de 1893. Si las exposiciones europeas eran conceptualizadas como una gran estrategia comercial global, la feria colombina de Chicago se caracterizó por ser una gran estrategia de propaganda geopolítica, en la que los Estados Unidos se presentó como el referente de un nuevo orden mundial.

Junto a la celebración de esta exposición, tuvo lugar un Congrèss auxilière intellectual llamado a crear una legislación para regularizar leyes generales como: inmigración, naturalización, privilegios internacionales para gobiernos extranjeros y sus ciudadanos, legislación para empleadores para disminuir la pobreza, la locura y el crimen, leyes sobre la habilidad productiva y también para el fomento de la prosperidad y la virtud, en fin, leyes para el Etablissement des principes de justice para el mundo.

Es importante llamar la atención que Guatemala, en un intento por capitalizar el poder generado por las llamadas exposiciones universales organizó su propia versión en 1897, durante la cual realizó de manera idéntica a la exposición de Chicago, un congreso jurídico, que buscaba unificar las legislaciones centroamericanas para estandarizar las variantes.

Por otro lado, el discurso introductorio del catálogo oficial, abunda en descripciones de encomio a la ciudad y a su exposición: No one can appreciate fully the magnitude and the significance of the microcosm at Chicago in 1893, la ciudad es presentada como un fenómeno so gigantic, so young, so rich, strong and powerful. ${ }^{2}$ El cuarto centenario del descubrimiento de América dio

2 Nadie puede apreciar plenamente la magnitud y la importancia del microcosmos en Chicago en 1893. Tan gigante, $\tan$ joven, $\tan$ rico, tan fuerte y poderoso. 
lugar para la celebración de cuatro siglos de ejemplar prosperidad del pueblo americano, que se da cita a orillas del Lago Chicago, y con ello, ofrecer al mundo la más grandiosa exhibición que se ha producido hasta ese momento. La ciudad y su exhibición se convierten así en la esencia misma del espíritu de progreso americano y en el centro de atracción del momento, robando con ello el protagonismo que tuviera París cuatro años antes y ensombreciendo la exposición universal de Madrid del año anterior. Millones de dólares y un plan de exposición con infinitos detalles en su ejecución, se proponían una de las mayores empresas de los tiempos modernos.

El entusiasmo por la exposición fue tal, que su catálogo oficial afirma que, después de la misma, el mundo entero estará dividido en dos grandes clases: los que vinieron a la feria y los que no asistieron.

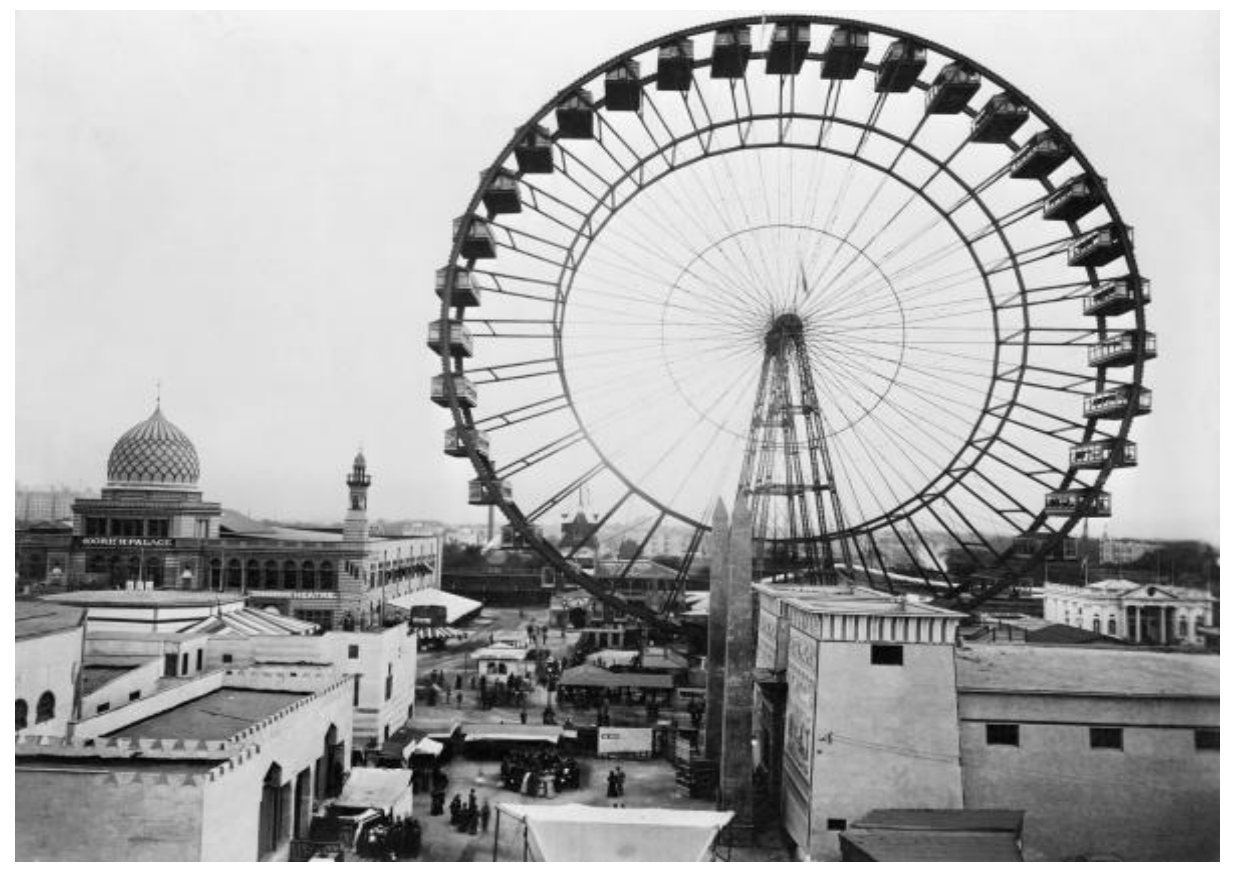

Imagen 5. La Rueda de Chicago en el centro del centro ferial, en la exposición mundial de 1893. Fuente: Explore PAHistory.com

Vista panorámica de la Feria Universal de Chicago, con la famosa rueda en el centro de la exposición. El tamaño y presencia de la estrucutra, pretendía competir con la magnificencia con la que fue diseñada la Torre Eiffel en París 1889.

El mayor propósito de la exposición sería convertirse en el nuevo centro del mundo, tanto a nivel de la educación y la cultura, proponiendo una nueva visión 
de la participación femenina, con la que el patriarcado capitalista norteamericano se proyecta como un ejemplo ético, hasta en la arquitectura con la cual impone nuevas formas de construcción y un estilo elitista clásico a todo el mundo civilizado Así como la exposición de París de 1889 tiene como centro la Torre Eiffel, la Fair tiene como centro The ferris wheel (Imagen 5). Esta maquinaria de diversión pública logra desplazar el sentido de la torre parisina, estática y representativa del arte y la técnica industrial, hacia el sentido de diversión masiva, propio de la Rueda de Chicago, que a partir de la fair se logra difundir de manera auténticamente global y se convierte en el centro de las ferias de juegos mecánicos a lo largo y ancho de todo el orbe.

La rueda girante, la mayor estructura giratoria metálica hecha hasta ese momento, con un peso de 56 toneladas, con seis carros arrastrados al mismo tiempo y con un tiempo de giro de 20 minutos y un motor de dos mil caballos de fuerza, fue ubicada en la céntrica avenida de la exposición llamada themid way plaisance, la cual simulaba un recorrido por las más exóticas ciudades del mundo.

La encantada White City -the city of Aladdins palaces, asumió un rol importante a nivel mundial en materia de vanguardia arquitectónica, la intención de los organizadores era que influenciara no sólo la arquitectura de todo Estados Unidos sino a todo mundo, de manera indefinida. La gigantesca empresa constructiva y la intrincada maquinaria ejecutiva de la feria, dictarían las pautas a nivel mundial, con lo cual se ejercía una hegemonía estética en materia arquitectónica. Para lograr este objetivo se invitaron a los más importantes arquitectos conocidos en la época, diseñadores de estructuras, los más expertos artesanos para ejecutar los diseños, artistas famosos que realizaron las ornamentaciones y un gigantesco ejército de trabajadores peones de la construcción. Algunos de los mayores edificios construidos expresamente para la exposición son el Women's temple, el edificio de transporte y Logia Masónica. El estilo aristocrático del Este americano se ve enriquecido por el exotismo de la arquitectura asiática de Siam y China, y las pirámides mexicanas, las cuales influirían en la arquitectura de vanguardia de los Estados Unidos y en el mundo del siglo XX.

La exposición colombina fue la primera en la que se incluyó como un tema particular a la mujer, tanto es así que se construyó un edificio, uno de los principales de la exposición, The Women's Temple, en el interior del cual se desarrollaba el tema de la mujer en la historia, así como sus virtudes: Sacrifice, Charity, Maternity and Love y fue dedicado de manera especial a la Reina Isabel de España. Dentro del edificio se construyó uno de menor tamaño destinado al tema: Childrens. El cuerpo encargado de la organización de la participación femenina, The Board of Lady Managers, fue liderado por Mrs. Potter Palmer, nuera del presidente Cleveland. La invitación fue extendida al resto de los países 
participantes: Dinamarca se niega a participar, Italia y Francia, lo hacen junto a México, cuya encargada es pariente del presidente Porfirio Díaz.

A diferencia de París en 1889, en el que la mujer era vista como un potencial consumidor, por lo cual se presentaron apartados dirigidos especialmente a productos femeninos. En Chicago se rescató la figura de la mujer como un sujeto social vinculado al poder, esto coincide con lo afirmado por Hobsbawm en el sentido de que la mujer que adquirió protagonismo a finales del XIX en el contexto imperialista, fue la mujer de la clase dirigente.

Se advierte en la presentación del tema en los catálogos de Chicago, una intención de presentar a los países extranjeros como no civilizados en relación al Chicago civilizado, pues se afirma que acá la mujer tiene un lugar protagónico que no tendría en sus países de origen tal y como se observa en este texto: Foreign women have been placed in absolute control at Jackson Park, in positions where the sex would not be given an opportunity abroad.

\section{La tensión entre el viejo y el nuevo mundo}

La exposición de Chicago dejó entrever una tensión entre los viejos imperios europeos y la emergente hegemonía estadounidense. La delegación de Inglaterra, por ejemplo, reclamó la importancia de su país como primera potencia industrial y con ello, su legítimo derecho de ejercer su dominio como Imperio informal. Se debe tener en cuenta que a pesar de su afinidad cultural con los EEUU, Inglaterra era la única potencia europea que continuaba ejerciendo presión por la conquista de territorios americanos, como sus enclaves en el Caribe, y la intrusión que en 1892 se encontraba realizando en Venezuela, país que acudió al Presidente Cleveland por ayuda, quien invocando la doctrina Monroe, consigue expulsar a Inglaterra. Sobre este particular, llama la atención que el único país que se presenta en un lugar destacado en la exposición es Venezuela comprobándose con ello la vocación pragmática de este tipo de eventos culturales.

Por otra parte, la relación con España no puede ser más compleja. En primer lugar, se tenía en cuenta que años antes Estados Unidos le disputó amplios territorios y en segundo lugar, pocos años después le disputó sus últimos reductos de posesión en ultramar: Cuba, Filipinas y Puerto Rico. Así mismo, en términos simbólicos y retóricos, el conflicto no era menor, ya que se celebraba el cuarto centenario un año después que lo hizo España, y se revivió la amarga polémica del año anterior, en donde se puso en entredicho la validez de Cristóbal Colón como descubridor del continente y su origen español, en el contexto de la exposición de Madrid de 1892. Como anécdota sintomática de este conflicto, cabe señalar la ceremonia de inauguración en la que The President of the United 
States and the Duke of Veragua, the lineal descendant of Columbus, were the guests of honor on this occasion ${ }^{3}$ y la llegada de la Infanta Eulalia de España, quien arribó a la exposición por el lago a la ciudad de Chicago, acompañada de las tres carabelas: la Niña, la Pinta y la Santa María y un enorme barco vikingo lo cual revelaba una compleja operación de legitimación-deslegitimación simbólica hacia lo poco que quedaba del antiguo imperio español.

Por otro lado, uno de los más importantes espacios de la exposición fue el Convento de la Rábida, una réplica parfaitement authentique del monasterio de los padres franciscanos que dieron abrigo a Cristóbal Colón en las calles de España. Fue el lugar que concentró toda la temática relacionada con España y con el mundo hispano, reduciendo de manera arbitraria un área geográfica muy amplia y compleja (toda Iberoamérica), es reducida en términos simbólicos a una cultura homogénea. Cabe destacar el hecho que, mientras las otras delegaciones europeas ocupaban un edificio para sus exposiciones, España y sus antiguas colonias ocupaban el espacio destinado al tema etnológico, en donde las piezas fundamentales serían las reliquias de Colón y de la Reina Isabel, así como el mapa del Ducado de Veragua ubicado en el Isthmus de Panamá en tiempos de la colonia. También se encontraban: Original papers relating to Columbus; Loaned by the Duke of Veragua y by the Duchess of Berwick and Alba, la cristianización del continente y la exhibición del Vaticano, entre muchas otras secciones representativas de la colonia española.

El tema etnológico desarrollado en la Rábida abarcó Ancient religions, games and folklore, an attractive feature in ethnology is the study of folklore, including the religious faiths and ceremonies, the household tales, traditions and myths, and the evolution of games and toys ${ }^{4}$. Este tema también se desarrolló en otros espacios de la exposición de Chicago en relación a los antepasados norteamericanos como los enterramientos de Ohio y otros pueblos de los Estados Unidos.

El texto hace mención sobre Mexico and the Central and Southamerica Republics a las cuales considera our Foster children, y destaca su importancia por Their wealth of cereals, precious metals and priceless gems. ${ }^{5}$ Por otro lado, estos países son importantes como tema arqueológico, tal es el caso de las Ruinas de Yucatán, o las momias de Perú. Centroamérica se menciona de manera muy marginal, solamente hacen su aparición Guatemala que llama la atención por su edificio neoclásico con pórtico de orden dórico. Costa Rica

3 El Presidente de los Estados Unidos y el Duque de Veragua, descendiente lineal de Cristóbal Colón, fueron los invitados de honor en esta ocasión

4 Las religiones antiguas, juegos y folclore, una característica atractiva en la etnología es el estudio del folklore, incluyendo las creencias religiosas y las ceremonias, los cuentos, las tradiciones y mitos, y la evolución de los juegos y los juguetes.

5 Su riqueza en cereales, metales preciosos e inestimables gemas. 
con una arquitectura de estilo español enmarcado en un jardín tropical de aves, flores, café y banano, principalmente. Las colecciones sobre material arqueológico centroamericano, se mencionan como propiedad de museos como el Peabody que hace investigaciones en la región y el museo de Berlín, y se encuentran exhibidos no en los apartados de Centroamérica sino como parte de las posesiones de estas potencias imperiales.

Las repúblicas de El Salvador, Nicaragua y Honduras no son mencionadas, sí se hace marcada referencia al Ducado de Veragua (hoy Panamá) aunque a la fecha no había sido constituido como República. Tampoco se hace ninguna mención a la vía del tránsito en Nicaragua ni al proyecto de construcción de un canal interoceánico, a pesar de que había sido tema importante en la exposición de 1889 en París (Cubero Barrantes, 2016, p. 162-203).

\section{Conclusiones}

La exposición de Madrid de 1892 presenta una doble tensión con América, la primera con sus antiguas colonias y la segunda con los Estados Unidos. Estas dos tensiones quedan claramente dibujadas en la sintaxis de los tres tomos de su amplísimo catálogo, el primero de los cuales está dedicado a los Estados Unidos, éste contiene no sólo informaciones sus Estados sino también sobre los tesoros arqueológicos procedentes de las antiguas posesiones españolas en América, ahora estudio en las universidades norteamericanas. El segundo tomo está dedicado al resto del mundo, mientras que el tercero está dedicado a España, el país anfitrión. Este último tomo, no sólo presenta los tesoros propiamente españoles, sino que abunda en descripciones, cartas, capitulaciones, y un sinnúmero de documentos entre los cuales destacan algunos de La Luisiana, Las Carolinas, La Florida y otras muchas extensas posesiones españolas ahora en manos de los Estados Unidos. También muestra especial énfasis en los tesoros arqueológicos de sus antiguas posesiones coloniales como México y Perú, asimismo presenta reliquias históricas provenientes de Filipinas y Cuba, sus últimas posesiones en ultramar, también en disputa con los Estados Unidos.

De manera sintomática, en el contexto de la exposición madrileña, tienen lugar agrias discusiones en torno a la legitimidad española y en particular la de Cristóbal Colón como descubridor de América. Por otro lado, se destaca su nacionalidad genovesa y la llegada de los vikingos a las costas americanas mucho antes que las expediciones españolas. A pesar de que España deseaba presentarse ante el mundo como una monarquía ilustrada, y por lo tanto moderna, sigue soñando con un pasado de gloria y dominio, anclada a viejos paradigmas coloniales que confrontan la superioridad de la civilización europea con la barbarie del indígena americano. 
Una de las mayores tensiones que parece oscurecer todo el fondo de la exposición de Madrid es la decadencia del modelo colonial español, que ve ascender a su principal adversario, el naciente poderío norteamericano. En medio de la retórica anticuada y de la pérdida de sus viejas posesiones en América, debe enfrentar el avance de los intereses norteamericanos y su nueva estrategia imperialista, que no necesita de las pesadas cargas de la administración colonial, pues usa como herramientas de dominación sus estrategias discursivas y la persuasión de su poderío económico y militar.

De manera similar a lo ocurrido en Madrid, pero de manera inversa, la exposición de Chicago entra en tensión con el viejo mundo. Por un lado, la imitación de la exposición de París de 1889 es evidente y explícita, se copia todo el modelo de gestión y ejecución mientras que la ambientación de la exposición, es una especie de calco de ciudades europeas, al punto de simular un golfo veneciano a las orillas del Lago Chicago, con estatuas de figuras del arte, la música y la ciencia europeos adornando plaza y jardines por todos los rincones. La tensión con Madrid es también evidente, por todos los recursos retóricos, que, de manera contradictoria, ya adulan ya afrentan, la participación española. La misma Inglaterra, aliada natural de los Estados Unidos, se siente desplazada ante este nuevo protagonismo y reclama haber sido la primera potencia mundial en realizar exposiciones universales. El marco sociohistórico no solo muestra tensiones permanentes, en los procesos de acumulación de nuevos territorios en manos de Estados Unidos, sino también en la prohibición manifiesta o velada de intervención europea en cualquier rincón del Continente Americano, y en el plano más general, se observa el ascenso del modelo de imperialismo informal de los Estados Unidos, que pugna por una hegemonía global, mientras Europa ve derrumbarse el viejo modelo del colonialismo formal.

El lujo y esplendor de la exposición de Chicago no logra esconder las contradicciones internas del nuevo proceso civilizatorio. El uso excesivo de la fuerza policial, para contener el crimen y para reprimir y expulsar a sujetos indeseables, es ampliamente publicitado como una virtud americana. Estatuas de policías, celebración de represiones policiales, el excesivo orden y control de la exposición que sólo permite un recorrido único y regulado, son algunos signos del nuevo modelo de civilización en marcha. El racismo campea en la discursividad de los catálogos que retrata a los indígenas americanos y las culturas originarias del continente dentro de la nomenclatura clasificatoria de etnología. Los negros, asiáticos y antillanos son citados como parte de un sistema de control estadístico, pero no como ciudadanos formales. El sur de América es conceptualizado como un sur recurso de manera similar como es vista África, desde la perspectiva europea, mientras que el sujeto social mujer es utilizado como un elemento propagandístico, cuya inclusión en la dinámica 
social y laboral es publicitada como un signo de modernidad y civilización, mientras se le asignan los roles tradicionales de madre abnegada y sumisa que le corresponde dentro del modelo patriarcal tradicional (Cubero Barrantes, 2016, p. 214-216).

Debido al importante influjo de las exposiciones universales del siglo XIX en nuestros museos nacionales centroamericanos, nuestras élites intelectuales adoptaron y fortalecieron una serie de discursos dominantes que acabarían por convertirse en verdades sagradas y eternas, no cuestionadas por los públicos de los museos y que consecuentemente fueron asentándose en el pensamiento cotidiano con consecuencias para todo el complejo sistema de la cultura.

Esta serie de discursos conformaron una matriz de dominación ideológica que con sus distintas variantes en nuestros países centroamericanos, respondieron básicamente a los siguientes tópicos: una visión hetero-patriarcal misógina del mundo. Una lógica capitalista, que reduce todas las relaciones económicas a la práctica de un mercado global caracterizado por la búsqueda de nuevos consumidores, la explotación de la mano de obra y el agotamiento de los recursos de la naturaleza. El predominio de un canon de pensamiento cartesiano eurocéntrico, que se presenta como único y universal y que resulta en el epistemicidio o exterminio de cualquier forma de saber o conocimiento alternativo a Occidente. Imposición de códigos ético-estéticos eurocéntricos que bajo la forma de lo bueno y lo bello se impusieron en la doxa dominante del sistema de educación formal. Un esquema de actitudes de racialización del otro, cuya base de lo ideal descansa en una blanquitud inventada, llamada a imponerse sobre las poblaciones nativas y afrodescendientes. La importación de un sistema político basado en una democracia liberal representativa que responde a una lógica europea-noratlántica.

\section{Referencias bibliográfícas}

Boivin, M., Rosato, A. y Arribas, V. (2004). Constructores de otredad: Una introducción a la antropología social y cultural. Buenos Aires, Argentina: Antropofagia.

Chen Sham, J. (1999). Fray Gerundio de Campazas o la corrupción del lenguaje, sátira y escamoteo autorial. San José, Costa Rica: Universidad de Costa Rica.

Cubero Barrantes, G. (2016). La museología centroamericana como reproductora del discurso eurocentrista. Un análisis de los catálogos de la participación de Centroamérica en las exposiciones universales de París, Madrid, Chicago y Guatemala a finales del siglo XIX. (Tesis 
de doctorado, Universidad Nacional de Costa Rica). Recuperado de https://repositorio.una.ac.cr/bitstream/handle/11056/14448/Cubero\%20 Barrantes, $\% 20$ Guillermo.pdf? sequence $=1 \&$ isAllowed $=\mathrm{y}$

Grass, A. (1982). Los rostros del pasado. Diseño prehispánico colombiano. Bogotá, Colombia: Talleres Gráficos Arco.

Lotman, I. M. (1998). La semiosfera II: semiótica de la cultura, del texto, de la conducta y del espacio. Valencia, España: Editorial Cátedra.

Maldonado Torres, N. (2007) Sobre la colonialidad del ser: contribuciones al desarrollo de un concepto. En S. Castro-Gómez y R. Grosfoguel. (Eds.), El giro decolonial. Reflexiones para una diversidad epistémica más allá del capitalismo global (pp. 127-167). Recuperado de http://www. ceapedi.com.ar/imagenes/biblioteca/libreria/147.pdf

Montreal: Société des publications françaises. (1893). Guide General de la Ville de Chicago et de L'Exposition Colombienne de 1893. Recuperado de https://archive.org/details/cihm_06380/page/n7/mode/2up

Said, E. (2002). Orientalismo. Barcelona, España: Mondadori.

Sucesores de Rivadeneyra. (1893). Catálogo general, exposición históricoamericana de Madrid 1892. Recuperado de http:/www.cervantesvirtual. com/obra/catalogo-general-de-la-exposicion-historico-americana-demadrid--1892/

Van Dijk, T. A. (1999). Pragmática de la comunicación literaria. Madrid, España: Arcos Libros. 


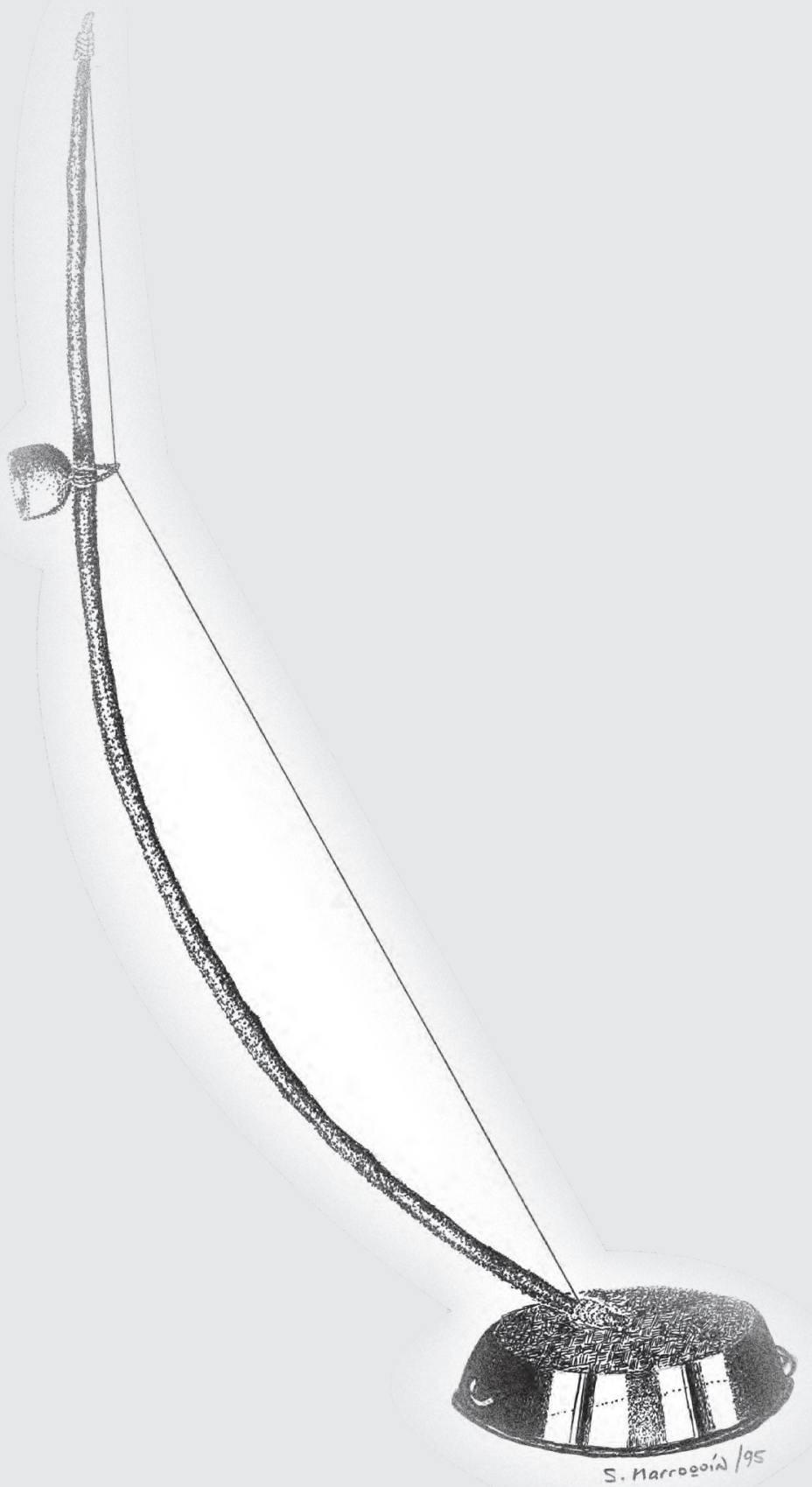

\section{Caramba}

Salvador Marroquín 